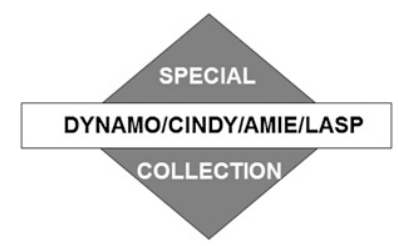

\title{
The Surface Diurnal Warm Layer in the Indian Ocean during CINDY/DYNAMO
}

\author{
ADRIAN J. MATTHEWS \\ Centre for Ocean and Atmospheric Sciences, School of Environmental Sciences and School \\ of Mathematics, University of East Anglia, Norwich, United Kingdom \\ DARIUSZ B. BARANOWSKI \\ Institute of Geophysics, Faculty of Physics, University of Warsaw, Warsaw, Poland \\ KAREN J. HEYWOOD \\ Centre for Ocean and Atmospheric Sciences, School of Environmental Sciences, University \\ of East Anglia, Norwich, United Kingdom \\ PiOTR J. FLATAU \\ Scripps Institution of Oceanography, University of California, San Diego, San Diego, California \\ SUNKE SCHMIDTKO \\ Centre for Ocean and Atmospheric Sciences, School of Environmental Sciences, University \\ of East Anglia, Norwich, United Kingdom
}

(Manuscript received 24 March 2014, in final form 10 September 2014)

\begin{abstract}
A surface diurnal warm layer is diagnosed from Seaglider observations and develops on half of the days in the Cooperative Indian Ocean Experiment on Intraseasonal Variability/Dynamics of the Madden-Julian Oscillation (CINDY/DYNAMO) Indian Ocean experiment. The diurnal warm layer occurs on days of high solar radiation flux $\left(>80 \mathrm{~W} \mathrm{~m}^{-2}\right)$ and low wind speed $\left(<6 \mathrm{~m} \mathrm{~s}^{-1}\right)$ and preferentially in the inactive stage of the Madden-Julian oscillation. Its diurnal harmonic has an exponential vertical structure with a depth scale of 4-5 m (dependent on chlorophyll concentration), consistent with forcing by absorption of solar radiation. The effective sea surface temperature (SST) anomaly due to the diurnal warm layer often reaches $0.8^{\circ} \mathrm{C}$ in the afternoon, with a daily mean of $0.2^{\circ} \mathrm{C}$, rectifying the diurnal cycle onto longer time scales. This SST anomaly drives an anomalous flux of $4 \mathrm{~W} \mathrm{~m}^{-2}$ that cools the ocean. Alternatively, in a climate model where this process is unresolved, this represents an erroneous flux that warms the ocean. A simple model predicts a diurnal warm layer to occur on $30 \%-50 \%$ of days across the tropical warm pool. On the remaining days, with low solar radiation and high wind speeds, a residual diurnal cycle is observed by the Seaglider, with a diurnal harmonic of temperature that decreases linearly with depth. As wind speed increases, this already weak temperature gradient decreases further, tending toward isothermal conditions.
\end{abstract}

\section{Introduction}

Ocean-atmosphere interaction is a key process in tropical weather and climate. The moisture flux from the

Corresponding author address: Dr. Adrian J. Matthews, School of Environmental Sciences, University of East Anglia, Norwich NR4 7TJ, United Kingdom.

E-mail: a.j.matthews@uea.ac.uk ocean to atmosphere increases approximately exponentially with sea surface temperature (SST) through the Clausius-Clapeyron and bulk flux relationships (Fairall et al. 1996b). These processes are core to the evolution of El Niño-Southern Oscillation (ENSO; Neelin et al. 1998) on interannual time scales. On shorter, intraseasonal time scales, ocean-atmosphere interaction has a significant role in the development and eastward propagation of the Madden-Julian oscillation (MJO; Flatau et al. 1997; 
Shinoda et al. 1998; Woolnough et al. 2000; Matthews 2004; Drushka et al. 2012) and also in the northwardpropagating intraseasonal oscillations observed in the Indian Ocean during the boreal summer (BSISO; Fu and Wang 2004; Seo et al. 2007).

Recently, attention has focused on ocean-atmosphere interaction on even shorter, diurnal time scales. A strong diurnal cycle of SST (up to $2^{\circ} \mathrm{C}$ magnitude) in the western Pacific was observed during the Tropical Ocean and Global Atmosphere Coupled Ocean-Atmosphere Response Experiment (TOGA COARE; Sui et al. 1997). This was particularly prevalent during the inactive stage of the MJO, with in situ conditions of high surface solar radiation flux and surface heating, and low surface wind speeds and weak vertical mixing. This diurnal cycle in SST is part of a diurnal warm layer that grows during the day through absorption of solar radiation in the top few meters of the ocean (Price et al. 1986; Fairall et al. 1996a; Gentemann et al. 2009; Prytherch et al. 2013). Nocturnal surface cooling and destabilization then mix up the diurnal warm layer overnight into the deeper mixed layer.

Observations of the diurnal warm layer have characterized its temperature profile as being approximately isothermal (Delnore 1972; Soloviev and Lukas 1997), decreasing approximately linearly with depth (Delnore 1972; Webster et al. 1996; Prytherch et al. 2013), or decreasing approximately exponentially with depth (Halpern and Reed 1976; Webster et al. 1996; Soloviev and Lukas 1997), depending on ambient wind conditions.

However, because of the shallow nature of the diurnal warm layer, it is difficult to measure. Observations of the diurnal warm layer have been mainly made using shipboard conductivity-temperature-depth (CTD) instruments or from moorings. However, both of these platforms have disadvantages. A vertical resolution of $1 \mathrm{~m}$ or finer is required near the surface. This is difficult to achieve using a conventional shipboard CTD, because of the wake around the CTD package disturbing the finescale structure of the diurnal warm layer and motion from the ship. Additionally, long ship deployments, such as would be necessary to capture the diurnal cycle in different stages of the MJO, are very expensive. For moorings, the buoy structure can distort the near-surface flow. In the presence of a diurnal warm layer, this has been found to bring warm water from near the surface down to the level of the sensor, leading to an overestimation of temperature of up to $1^{\circ} \mathrm{C}$ (Prytherch et al. 2013). Standard Argo floats (Gould et al. 2004) do not have the vertical or temporal resolution required to resolve the diurnal warm layer, typically only making one temperature measurement in the top $10 \mathrm{~m}$ and one profile every 5-10 days. However, ongoing deployment of Sounding Oceanographic Lagrangian Observer 2 (SOLO-II) Argo floats, with higher vertical resolution and profile frequency, may partially address this in the future.

This diurnal warm layer and diurnal SST cycle can have a significant effect on atmospheric convection. Typically, the diurnal cycle of precipitation over the tropical open ocean is weak, with a peak before sunrise (Gray and Jacobson 1977; Bowman et al. 2005). However, during periods of high solar radiation and weak winds, as well as a strong diurnal SST cycle, atmospheric convection over the ocean can behave similarly to that over land, with a strong diurnal cycle, growth of cumulus congestus, and a precipitation maximum in the late evening (Johnson et al. 1999).

This diurnal variability can then impact onto longer time scales, such as the MJO (Bellenger and Duvel 2009). For example, precipitation over the seas and islands of the Maritime Continent is predominantly accounted for by the diurnal cycle. Over this region, $80 \%$ of the MJO precipitation signal is directly accounted for by changes in the amplitude of the diurnal cycle of precipitation (Peatman et al. 2014). There is also a strong indirect effect, which also operates over the open ocean. The diurnal warm layer is the result of solar heating during the day being concentrated in a shallow layer only a few meters thick. This layer has a lower heat capacity, compared with a situation where the entire deeper mixed layer is heated. Hence, even though the diurnal warm layer is mixed back into the underlying mixed layer overnight, the daily-mean SST is higher than it would have been in its absence (Shinoda 2005; Mujumdar et al. 2011).

In a coupled ocean-atmosphere general circulation model (GCM), this rectification of daily-mean SST by the diurnal variability of SST can increase the longterm-mean SST by $0.2^{\circ}-0.3^{\circ} \mathrm{C}$ (Bernie et al. 2008), with a subsequent improvement in the mean precipitation. In their simulations, the MJO is also improved, resulting from the increase in intraseasonal SST variability that stems from the improved diurnal SST variability (Bernie et al. 2007). These and other studies (e.g., Klingaman et al. 2011) concluded that a very fine vertical grid spacing, of approximately $1 \mathrm{~m}$, is required in the upper layers of the ocean component to resolve the diurnal warm layer processes there. As most current oceanatmosphere GCMs have a grid spacing on the order of $10 \mathrm{~m}$ and are often only coupled daily, these processes are not resolved. This leads to a degradation in the simulation and forecasting of the MJO (Woolnough et al. 2007), and also errors in the mean climate.

Ocean gliders are a relatively new technology for observing the ocean (Eriksen et al. 2001). They can provide 

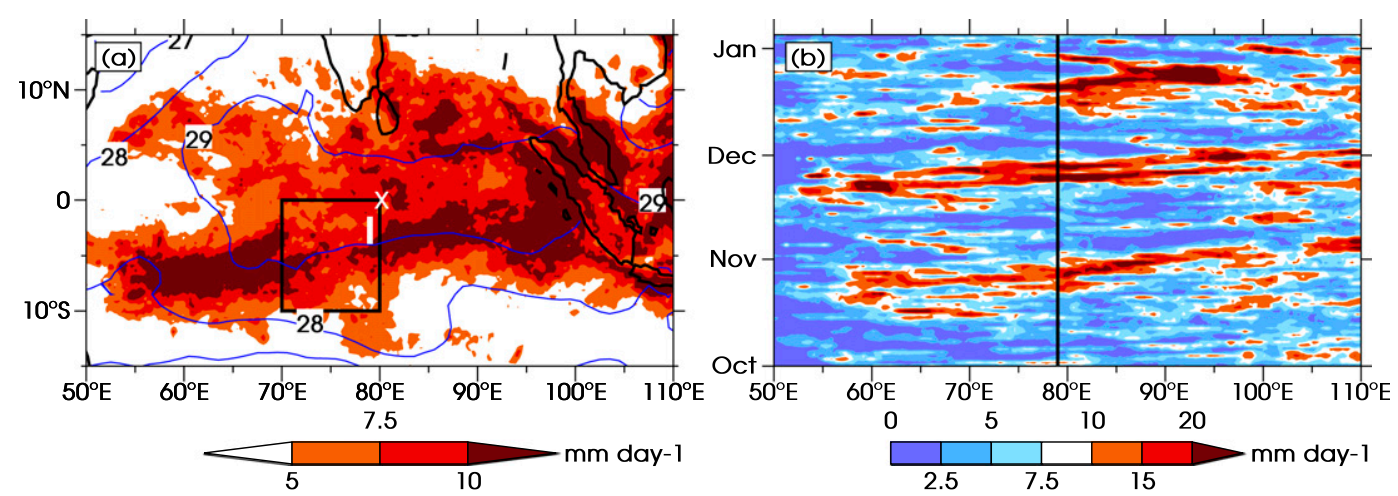

FIG. 1. (a) Time-mean TRMM 3B42 precipitation rate (color shading; $\mathrm{mm} \mathrm{day}^{-1}$ ) and SST (blue line contours; interval of $1^{\circ} \mathrm{C}$ ) over the study period of glider deployment during CINDY/DYNAMO (1 Oct 2011-5 Jan 2012). The box shows the approximate location of the CINDY/DYNAMO study area. The thick white line along $78^{\circ} 50^{\prime} \mathrm{E}$, between $1^{\circ} 30^{\prime}$ and $4^{\circ} \mathrm{S}$, shows the glider track. The white cross at $0^{\circ}, 80^{\circ} \mathrm{E}$ shows the location of the R/V Roger Revelle. (b) Time-longitude diagram of TRMM $3 \mathrm{~B} 42$ precipitation rate $\left(\mathrm{mm} \mathrm{day}^{-1}\right)$, averaged from $15^{\circ} \mathrm{S}$ to $15^{\circ} \mathrm{N}$. The thick black line shows the glider track.

very high-resolution data right to the surface, without the drawbacks of a shipboard CTD, and are relatively inexpensive to operate.

In this paper, the diurnal warm layer is analyzed using measurements from an ocean glider deployed as part of the Cooperative Indian Ocean Experiment on Intraseasonal Variability/Dynamics of the Madden-Julian Oscillation (CINDY/DYNAMO) international field experiment. CINDY/DYNAMO was designed to investigate ocean-atmosphere interactions and the initiation of the MJO in the Indian Ocean (Gottschalck et al. 2013). The high-quality, high-resolution data measured by the glider over a long deployment (approximately 100 samples of the diurnal cycle) allow the detailed structure of the diurnal warm layer to be analyzed in unprecedented detail. A further focus is how this varies under different environmental forcing conditions, particularly those associated with active and inactive phases of the MJO. Simple models of the diurnal warm layer under different environmental conditions are then developed, with the aim of informing (climate) model development.

\section{Data processing}

\section{a. External data sources}

Sea surface temperature data were extracted from the National Oceanic and Atmospheric Administration (NOAA) optimum interpolation (OI) version 2 dataset (Reynolds et al. 2002). These were obtained on a $1^{\circ} \times 1^{\circ}$ grid as weekly means, which were then interpolated to daily means for ease of analysis. Precipitation was diagnosed using the Tropical Rainfall Measuring Mission (TRMM) merged precipitation (3B42) dataset (Kummerow et al. 2000). The data were on a $0.25^{\circ} \times 0.25^{\circ}$ grid at 3 -h resolution. Daily-mean surface wind speeds were analyzed using the objectively analyzed air-sea fluxes (OAFlux) dataset (Yu et al. 2008). A self-consistent set of surface wind speed and shortwave radiative flux data was extracted from the TropFlux archive (Praveen Kumar et al. 2012). These daily-mean data were obtained on a $1^{\circ} \times 1^{\circ}$ grid.

\section{b. CINDY/DYNAMO and Seaglider deployment}

The DYNAMO field experiment concentrated on the $10^{\circ} \times 10^{\circ}$ box from $70^{\circ}$ to $80^{\circ} \mathrm{E}$ and from $10^{\circ} \mathrm{S}$ to $0^{\circ}$ in the equatorial Indian Ocean (Fig. 1a). It is at the heart of the high SST and maximum precipitation zone during the October 2011-January 2012 study period (line contours and color shading, respectively, in Fig. 1a). The global maximum in $\mathrm{MJO}$ precipitation is also in this region (Hendon and Salby 1994).

During CINDY/DYNAMO, three distinct MJO events passed through the study region. These can be seen as eastward-propagating bands of enhanced precipitation (above $10 \mathrm{~mm} \mathrm{day}^{-1}$ ) that cross the CINDY/DYNAMO $70^{\circ}-80^{\circ} \mathrm{E}$ sector, in late October, late November, and late December 2011 (Fig. 1b). In between the active MJO events, precipitation is suppressed (below $5 \mathrm{~mm} \mathrm{day}^{-1}$ ). Westerly wind bursts were associated with each MJO event (Moum et al. 2013), which forced a strong thermodynamical and dynamical ocean response (Shinoda et al. 2013). These MJO events were generally well forecast; inclusion of ocean-atmosphere coupling extended the skill of the MJO forecasts over this period by approximately 1 week, emphasizing the important role that such interactions played in these MJO events (Fu et al. 2013).

The MJO is conveniently diagnosed by the real-time multivariate MJO (RMM) index (Wheeler and Hendon 2004). 


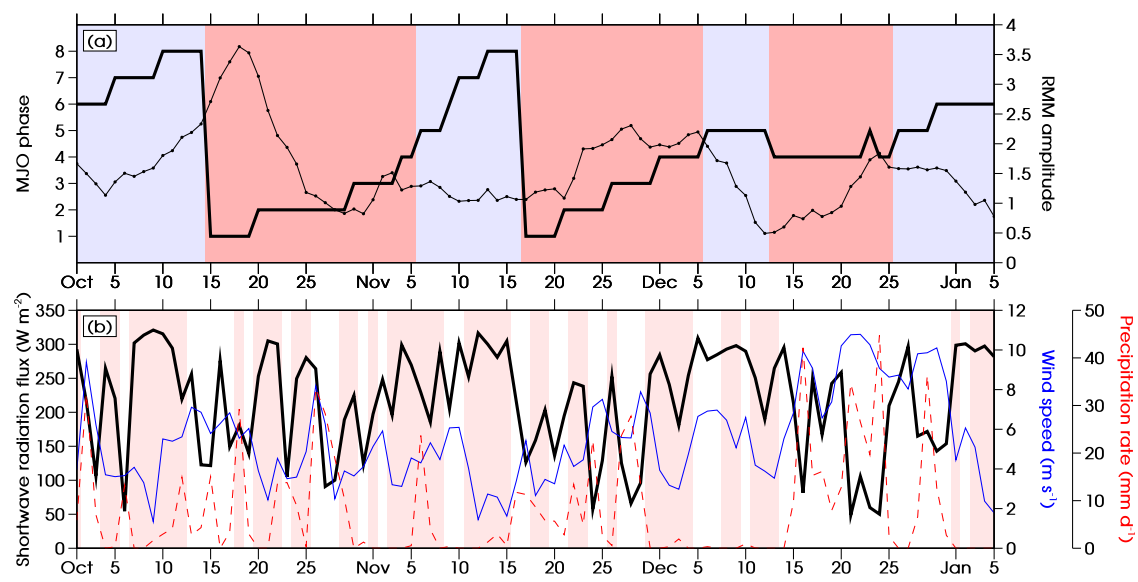

FIG. 2. Daily time series from 1 Oct 2011 to 5 Jan 2012 of (a) MJO RMM phase (thick line; left axis) and MJO RMM amplitude (thin line; right axis). MJO active phases (1-4) are shaded pink, and inactive phases (5-8) are shaded light purple. (b) Meteosat-7-derived shortwave radiation flux (black thick line; left axis), OAFlux surface wind speed (thin blue line; right axis), and TRMM precipitation rate (dashed red line; far right axis) at glider location. Days when a surface diurnal warm layer developed are shaded pink.

Time series of the amplitude and phase of the RMM index during CINDY/DYNAMO are shown in Fig. 2a by the thin and thick black lines, respectively. The RMM phase is expressed as an integer between 1 and 8 . Phases 1-4 indicate enhanced precipitation over the Indian Ocean; these are grouped into the "active" stage here. The RMM phases 5-8 indicate suppressed precipitation over the Indian Ocean: the "inactive" stage.

The Seaglider is a $1.8-\mathrm{m}, 50-\mathrm{kg}$ unmanned buoyancydriven autonomous underwater vehicle (AUV), instrumented for oceanographic research to measure pressure, temperature, conductivity, dissolved oxygen, chlorophyll fluorescence, and turbidity (Eriksen et al. 2001). A typical glider dive cycle has a sawtooth profile, with a dive phase from the surface to a specified depth (maximum $1000 \mathrm{~m}$ ) and a climb phase back to the surface.

The Seaglider SG537 "Fin" was deployed in the equatorial Indian Ocean on 14 September 2011 at $1^{\circ} 30^{\prime} \mathrm{S}$, $79^{\circ} 50^{\prime} \mathrm{E}$. It was then piloted southward along the $79^{\circ} 50^{\prime} \mathrm{E}$ meridian to $3^{\circ} \mathrm{S}$ (30 September 2011). The glider then made 10 transects between $3^{\circ}$ and $4^{\circ} \mathrm{S}$, arriving at $3^{\circ} \mathrm{S}$ for the final time on 5 January 2012. It then continued northward to the retrieval location (same as deployment, at $1^{\circ} 30^{\prime} \mathrm{S}, 79^{\circ} 50^{\prime} \mathrm{E}$ ) on 23 January 2012 , with a total mission duration of 131 days (Fig. 1a).

\section{c. Seaglider measurements and processing}

During the mission, the glider carried out 738 dive cycles, an average of 5.6 dive cycles per day or a time interval between the start of successive dives of $4.3 \mathrm{~h}$. Of these, 564 dives $(76 \%)$ were to $1000-\mathrm{m}$ depth; the remaining dives were to 300 or $500 \mathrm{~m}$. The glider vertical velocity is in the range $0.15-0.25 \mathrm{~m} \mathrm{~s}^{-1}$. Temperature and salinity were sampled every $5 \mathrm{~s}$, hence the effective vertical resolution is approximately $1 \mathrm{~m}$.

The glider data were corrected for thermal lags, sensor response time, and nonsynchronicity of sensor readings. Temperature and salinity data are accurate to $0.01^{\circ} \mathrm{C}$ and 0.01 , respectively. A further correction was made to the pressure measurements, to remove long-term drift of the pressure sensor over the mission duration and also to account for hysteresis within each dive. Further details are provided by Webber et al. (2014). The analysis was then carried out on the data gathered in the north-south sections from $3^{\circ}$ to $4^{\circ} \mathrm{S}$, between 1 October 2011 and 5 January 2012.

Before the dive phase of a dive cycle, the glider floats at the surface, engaged in satellite communications. The temperature sensor can be subjected to solar radiation and exposure to the atmosphere. When the dive phase starts, the temperature sensor can take several seconds to re-equilibrate to the water temperature. Hence, temperature measurements in the top few meters in the dive phase are unreliable. There are no such problems in the climb phase. Therefore, only data from the climb phases were used in this analysis.

The temperature time series was optimally interpolated (Bretherton et al. 1976) onto a two-dimensional grid, with regularly spaced pressure $p_{j}$ points (every $0.5 \mathrm{dbar}$ from 0.5 to $1000 \mathrm{dbar} ; 1 \mathrm{dbar}=100 \mathrm{hPa}$ ) and time $t_{j}$ points (every hour from the start to the end of the mission). First, an initial background temperature field was created at each grid point, using a weighted average of temperature observations from nearby in the pressure-time space. A 


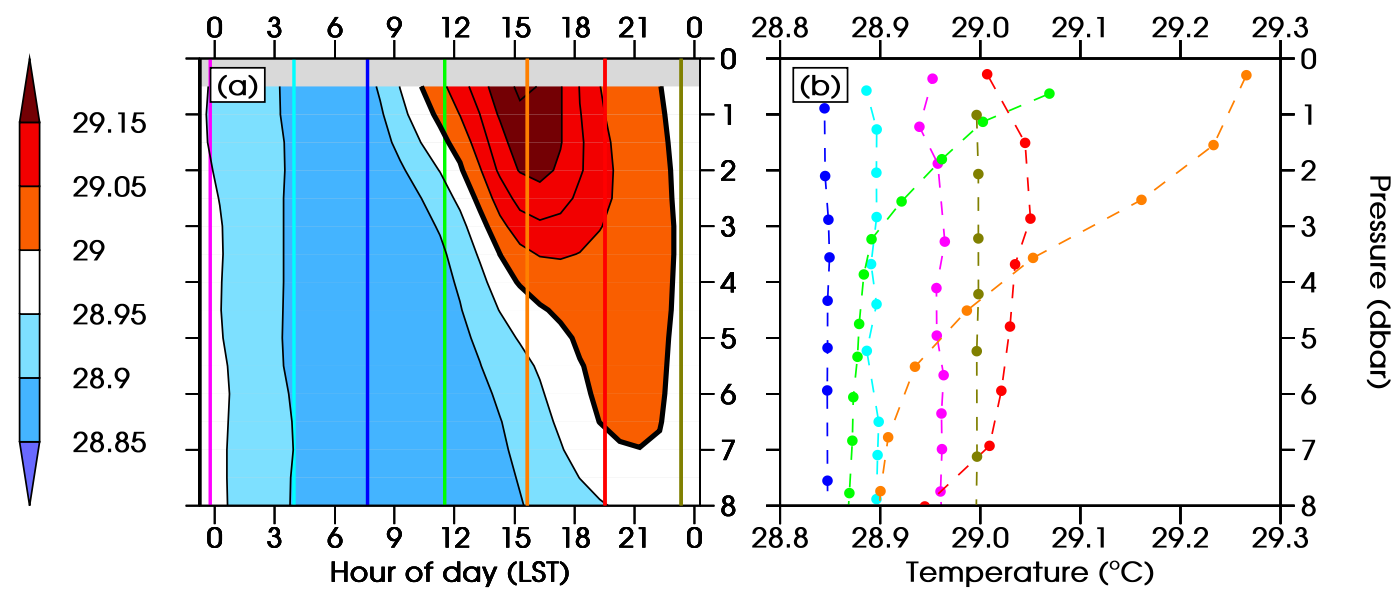

FIG. 3. (a) Optimally interpolated temperature $\left({ }^{\circ} \mathrm{C}\right)$ on 3 Dec 2011 . The contour interval for line contours and shading is $0.05^{\circ} \mathrm{C}$. The thick contour indicates the isotherm $T_{*}$ that is used to define the base of the diurnal warm layer. Temperatures above $T_{*}$ are shaded red. For this day, $T_{*}=29.0^{\circ} \mathrm{C}$. (b) Individual glider profiles on the same day. The vertical colored lines in (a) show the times of the glider profiles using the same color in (b).

Gaussian weighting function $w_{i j}$ was used to calculate the weighting that each temperature observation $T\left(p_{i}, t_{i}\right)$ contributes to the gridded value $T\left(p_{j}, t_{j}\right)$,

$$
w_{i j}=\exp \left\{-\left[\left(\frac{p_{i}-p_{j}}{p_{r}}\right)^{2}+\left(\frac{t_{i}-t_{j}}{t_{r}}\right)^{2}\right]\right\} .
$$

The $e$-folding scales $p_{r}$ and $t_{r}$ were defined as $1 \mathrm{dbar}$ and $3 \mathrm{~h}$, respectively, to reflect the scales of interest in this study. The background field was then used as the input to the optimal interpolation scheme. The covariances of the data were parameterized using the same Gaussian function [Eq. (1)] to calculate the analysis increment, which was then added to the background field to create the final optimally interpolated field. The grid spacings for the optimally interpolated field were chosen to be $\Delta p=$ $0.5 \mathrm{dbar}$ and $\Delta t=1 \mathrm{~h}$. Note that it is the $e$-folding scales $p_{r}$ and $t_{r}$ that govern the form of the gridded field. The choice of the output grid spacing is just a matter of presentational convenience.

An example of the optimal interpolation, and of the development of a diurnal warm layer, is shown in Fig. 3. The optimally interpolated temperature (color shading in Fig. 3a) on a sample day (3 December 2011) shows a well-mixed isothermal layer over at least the top $8 \mathrm{~m}$ at midnight [0000 local solar time (LST)]. There is then further cooling through the night until a minimum temperature of $28.87^{\circ} \mathrm{C}$ is reached at sunrise at $0600 \mathrm{LST}$.

Note that there is no gridded level at $0 \mathrm{dbar}$, as all contributing glider measurements would be below this level, introducing a bias. The first gridded level is at $0.5 \mathrm{dbar}$, which allows for contributing measurements above and below. Hence, for the purposes of this analysis, the temperature at $0.5 \mathrm{dbar}$ is referred to as the surface temperature. Also, as a 1 dbar pressure change is very close to a 1-m depth change, pressure and depth are used interchangeably in the following discussions.

During the day the surface warms, until it reaches a maximum of $29.21^{\circ} \mathrm{C}$ at $1500 \mathrm{LST}$. This diurnal warming is confined to the upper few meters. The temperature at $5 \mathrm{~m}$ at $1500 \mathrm{LST}$ is $28.95^{\circ} \mathrm{C}, 0.26^{\circ} \mathrm{C}$ colder than the surface. This is the stably stratified diurnal warm layer. As the solar radiation flux decreases through the afternoon, it is eventually overwhelmed by the cooling fluxes of latent heat, infrared radiation, and sensible heat, and the temperature of the diurnal warm layer decreases. After sunset (1800 LST) there is rapid cooling and mixing and a return to isothermal conditions at 0000 LST the next day.

The colored vertical lines in Fig. 3a show the times of the seven glider profiles during that day (Fig. 3b), which the optimally interpolated temperature field in Fig. 3a was effectively constructed from. Visual inspection reveals a very close agreement of the optimally interpolated temperature with the input temperature profiles.

\section{d. Meteosat-7-derived surface solar radiation flux}

The development of the diurnal warm layer depends on the surface flux of solar radiation. Direct measurements of this flux are not available at the glider location. However, variations in surface solar radiation flux are mainly driven by changes in convective clouds, which also drive changes in outgoing longwave radiation (OLR). Using a novel method, a proxy time series of solar radiation flux at the glider location can be constructed from satellite measurements of OLR at the glider location, using a conversion derived from surface solar radiation flux measurements made at the R/V Roger Revelle, stationed nearby (Fig. 1a). The details of the methodology 

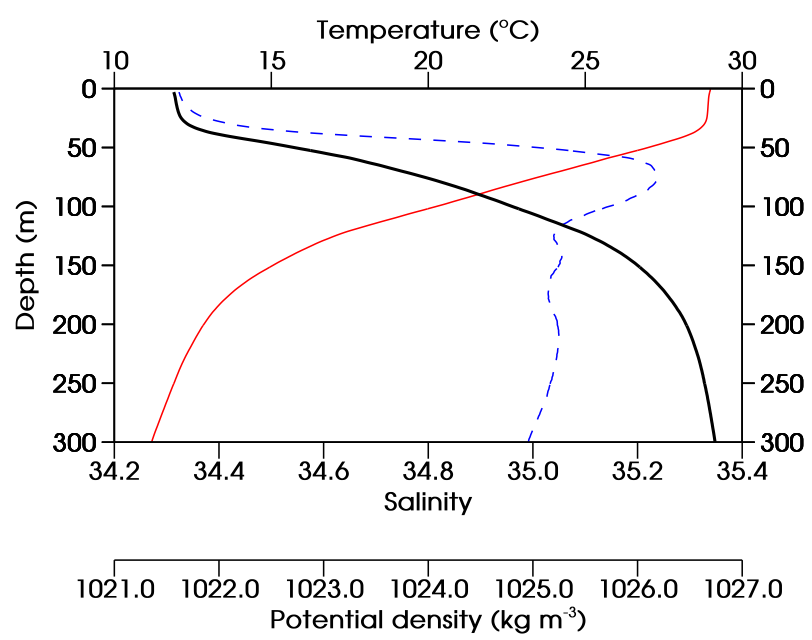

FIG. 4. Mean profiles of temperature (red solid line), salinity (blue dashed line), and potential density (black thick line) from the optimally interpolated glider data.

are given in appendix A. The proxy time series for the surface solar radiation flux at the glider location (black line in Fig. 2b) shows clear variability on day-to-day and intraseasonal time scales.

\section{Overview}

\section{a. Mean profile}

The diurnal and intraseasonal variability of the upper ocean are perturbations to, and strongly influenced by, the background thermodynamic structure. The mean temperature profile over the Seaglider deployment (1 October 2011-5 January 2012) has a surface mixed layer at $29.0^{\circ} \mathrm{C}$ over the top 30-m depth (Fig. 4, red solid line). Below this, the temperature decreases with depth through the thermocline, with, for example, the depth of the $20^{\circ} \mathrm{C}$ isotherm at $105 \mathrm{~m}$. Between 150 and $200 \mathrm{~m}$, the temperature gradient decreases; below that is the deep ocean. Temperature decreases monotonically with depth; hence, the temperature stratification is stable everywhere.

The mean salinity profile (Fig. 4a, blue dashed line) exhibits a surface fresh layer (34.32). At 25-m depth, the salinity increases rapidly, to a maximum of 35.23 at $75-\mathrm{m}$ depth. This "subtropical underwater" (O'Connor et al. 2005 ) originated at the surface in the subtropics, where evaporation exceeds precipitation, leading to the high salinity values. Below the salinity maximum, the mean profile becomes fresher with depth. Hence, the salinity stratification is unstable here. However, as the (potential) density is mainly controlled by the temperature variation over these tropical temperature and salinity ranges, this unstable salinity stratification does not lead to an unstable density stratification. Density increases monotonically with depth (Fig. 4a, thick black line), and the mean profile is statically stable at all levels. A detailed hydrographical analysis is given by Webber et al. (2014).

\section{b. Generic diurnal variability}

The day-to-day evolution of the temperature structure of the ocean surface boundary layer is shown for the sample month of November 2011 (Fig. 5). At the beginning of the month, the seasonal mixed layer is relatively cool (less than $29.2^{\circ} \mathrm{C}$ ). This coincides with the end of the active stage of the first MJO event on 5 November (Fig. 2a). By mixed layer, we mean the bulk mixed layer of depth order $20 \mathrm{~m}$, upon which a diurnal warm layer is superimposed at the surface. The MJO then moves into its inactive stage over the Indian Ocean. The mixed layer warms considerably, to above $29.6^{\circ} \mathrm{C}$ by 15 November. On 17 November the MJO enters the active stage of the second MJO event, and the mixed layer rapidly cools to below $29.0^{\circ} \mathrm{C}$ by 25 November. This local evolution of the mixed layer temperature (as measured by the Seaglider) is remarkably consistent with the expected sea surface

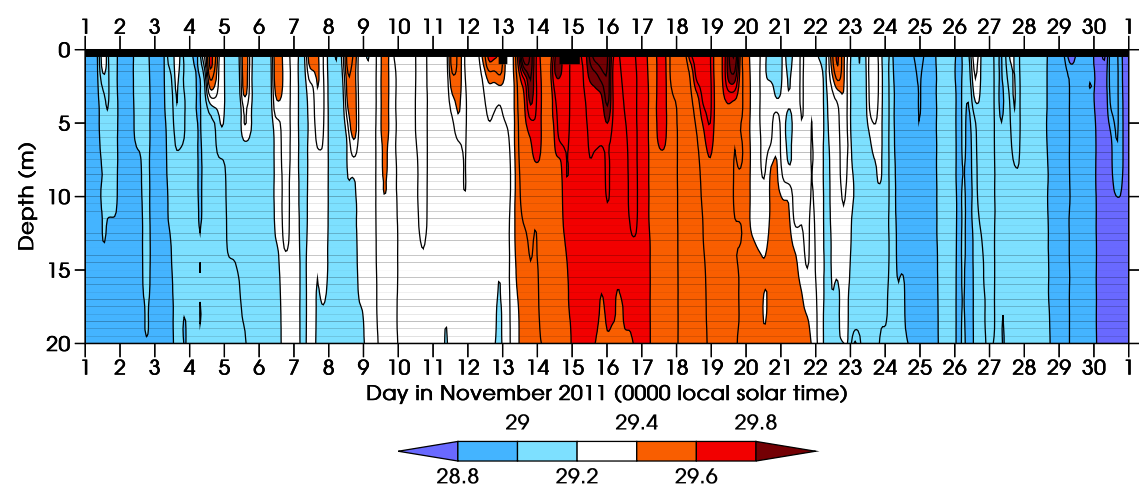

FIG. 5. Depth-time section for optimally interpolated glider temperature during November 2011. Contour interval is $0.2^{\circ} \mathrm{C}$. See legend for shading levels. Tick marks on the horizontal axis correspond to 0000 LST for each day. 
temperature cycle in a canonical MJO cycle (e.g., Shinoda et al. 1998), in both magnitude and phase.

Superimposed on this intraseasonal variability is a clear diurnal cycle in temperature, especially in the upper $5 \mathrm{~m}$. The tick marks on the time axis in Fig. 5 are at 0000 LST (midnight). A diurnal warming in the upper few meters by over $1^{\circ} \mathrm{C}$ is observed on many days, peaking in the early afternoon. This diurnal warm layer occurs throughout the cycle of the MJO during November 2011. Similar behavior was observed in the other months (not shown). However, the diurnal variability appeared to be particularly strong during the inactive stage of the MJO (6-16 November 2011).

\section{Diurnal warm layer occurrence}

The sample day of 3 December 2011, which was used to illustrate the optimal interpolation technique, is also a clear example of the development of a diurnal warm layer (Fig. 3a). The surface $(0.5 \mathrm{~m})$ temperature increases from a minimum at sunrise $(0600 \mathrm{LST})$ of $T_{06}=28.85^{\circ} \mathrm{C}$ to a maximum value of $T_{\max }=29.20^{\circ} \mathrm{C}$, at $1500 \mathrm{LST}$. In the following analysis, a technique is derived to objectively determine the existence of a surface diurnal warm layer and to quantify the effect the diurnal warm layer has on the SST.

A convenient measure of the depth of the warm layer is the depth $d_{\mathrm{WL}}$ of a fixed isotherm $T_{*}$,

$$
d_{\mathrm{WL}}=-z\left(T=T_{*}\right) .
$$

Here, we use $z$ as the vertical coordinate (positive upward, with $z=0$ at the surface) and $d$ for depth (which is always positive). The value of the isotherm is determined for each day individually. It should lie between the minimum and maximum values and is defined as

$$
T_{*}=\max \left[T_{06}+\alpha\left(T_{\max }-T_{06}\right), T_{06}+0.1^{\circ} \mathrm{C}\right] .
$$

The parameter $\alpha$ can be chosen from the range $0<\alpha<1$. It should be as small as possible to allow for as much of the diurnal warming as possible to be included in the definition of the diurnal warm layer. However, if $\alpha$ is too small, the analysis is sensitive to noise. A value of $\alpha=0.3$ was found to be suitable. To account for days when a diurnal warm layer did not develop or was not well defined, a minimum value of $T_{*}=T_{06}+0.1$ is specified, which also reduces sensitivity to noise.

For the sample day in Fig. $3 \mathrm{a}, T_{*}=29.0^{\circ} \mathrm{C}$. The thick contour at $29.0^{\circ} \mathrm{C}$ and the red shading for temperatures above $29.0^{\circ} \mathrm{C}$ in Fig. 3a illustrate the depth and extent of the diurnal warm layer on 3 December 2011.

The development of the (optimally interpolated) temperature profile during 3 December 2011 is shown from the surface to below $35 \mathrm{~m}$ in Fig. 6a. In an idealized framework, the vertical structure can be characterized by a three-layer model, with a temporally developing diurnal warm layer above a deeper mixed layer, which itself lies above a thermocline layer. For example, at 1700 LST 3 December 2011, there is a clear diurnal warm layer with a surface $(0.5 \mathrm{~m})$ temperature of $29.2^{\circ} \mathrm{C}$, which extends downward by a few meters (Fig. 6a). Below this, there is a seasonal mixed layer at a temperature of approximately $28.7^{\circ} \mathrm{C}$.

An idealized representation of the diurnal warm layer, as well as underlying mixed layer and thermocline layer, will now be constructed, with the ultimate purpose of calculating the effect of the warm layer on the mean SST. At any given time, an idealized representation of the warm layer is an isothermal layer of temperature $T_{\mathrm{WL}}$ and depth $d_{\mathrm{WL}}$ (Fig. 6b). The warm layer temperature $T_{\text {WL }}$ is calculated such that the idealized warm layer has the same heat content as the actual water column between the surface and the base of the warm layer at $d_{\mathrm{WL}}$,

$$
T_{\mathrm{WL}} d_{\mathrm{WL}}=\int_{-d_{\mathrm{wL}}}^{0} T(z) d z
$$

A method was developed to determine where a diurnal warm layer formed on a particular day, by comparing two definitions of the mixed layer depth. The first definition is the depth $d_{\text {MLsfc }}$ at which the temperature is $0.2^{\circ} \mathrm{C}$ less than the surface temperature $T_{\text {sfc }}$ (de Boyer Montégut et al. 2004),

$$
d_{\mathrm{MLsfc}}=-z\left(T=T_{\mathrm{sfc}}-0.2^{\circ} \mathrm{C}\right) .
$$

Note that the surface temperature defined here is actually the temperature at the highest available level, which is at $0.5-\mathrm{m}$ depth. In the absence of a diurnal warm layer, this definition can give a mixed layer depth of tens of meters in the study region. However, with a well-developed diurnal warm layer in the afternoon, this definition would give a mixed layer depth of only $4 \mathrm{~m}$ (Fig. 6b). Hence, this definition of the mixed layer depth is sensitive to diurnal warm layer formation.

The second definition is of the depth of the seasonal mixed layer $d_{\mathrm{ML}}$, which is defined here as the depth at which the temperature is $0.5^{\circ} \mathrm{C}$ less than the temperature at $10 \mathrm{~m}$,

$$
d_{\mathrm{ML}}=-z\left(T=T_{10 \mathrm{~m}}-0.5^{\circ} \mathrm{C}\right)
$$

This is not sensitive to diurnal warm layer formation.

These two definitions of the mixed layer depth can be used to define whether a diurnal warm layer develops on any given day. If a diurnal warm layer does develop, 

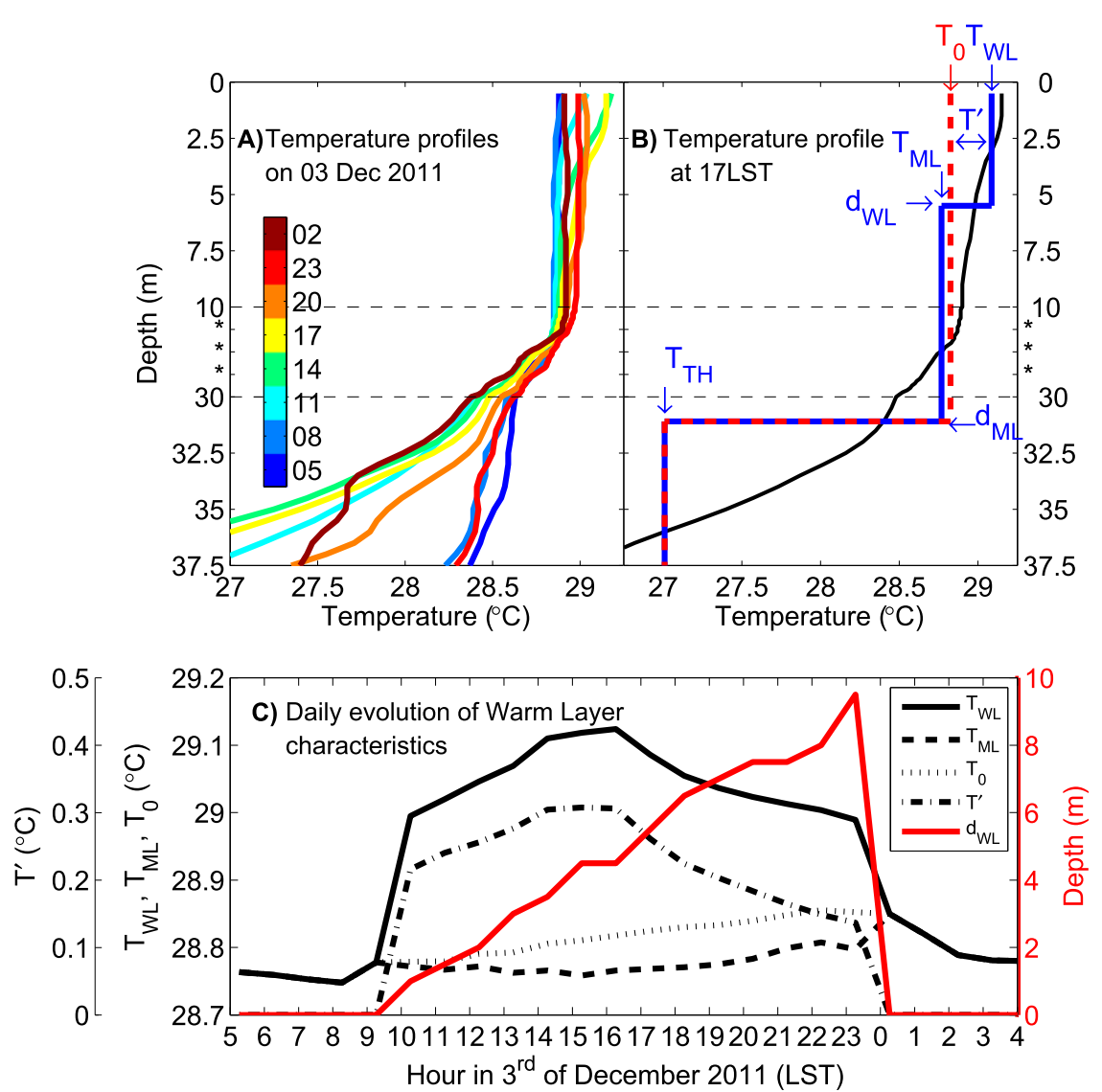

FIG. 6. (a) Temperature profiles of optimally interpolated glider data every $3 \mathrm{~h}$ from $0500 \mathrm{LST}$ 3 Dec to 0200 LST 4 Dec 2011. The colors of the individual profiles correspond to the times (LST) in the legend. Note the discontinuity in the vertical axis at 10 and $30 \mathrm{~m}$. (b) Temperature profile of optimally interpolated glider data at 1700 LST 3 Dec 2011 (black solid line). The idealized three-layer (two-layer) model fitted to this profile is shown by the thick blue (dashed red) line. Annotations show the values of the layer temperatures and depths of interfaces between the layers. (c) Time series of warm layer temperature $T_{\mathrm{WL}}$ (thick black solid line), mixed layer temperature $T_{\mathrm{ML}}$ (black dashed line), mixed layer temperature in two-layer model $T_{0}$ (thin black solid line), temperature anomaly due to existence of warm layer $T^{\prime}$, and depth of warm layer $d_{\mathrm{WL}}$ (red solid line) during 3 Dec 2011.

then the minimum value during that day of the mixed layer depth defined relative to the surface $\left[\min \left(d_{\text {MLsfc }}\right)\right]$ will be small, compared with the (daily mean) value of the mixed layer depth defined relative to the 10-m reference level [mean $\left.\left(d_{\mathrm{ML}}\right)\right]$. If no diurnal warm layer develops, then the two definitions of the mixed layer depth will return similar values. A scatterplot of $\min \left(d_{\text {MLsfc }}\right)$ against mean $\left(d_{\mathrm{ML}}\right)$ (Fig. 7) shows two clusters, conveniently divided by the line $\min \left(d_{\mathrm{MLsfc}}\right)=14.5 \mathrm{~m}$. Hence, a diurnal warm layer is defined to exist if

$$
\min \left(d_{\mathrm{MLsfc}}\right)<14.5 \mathrm{~m} .
$$

An idealized isothermal mixed layer is then defined, with a mixed layer temperature $T_{\mathrm{ML}}$ such that the heat content of the idealized mixed layer is the same as the heat content of the water column between the base of the diurnal warm layer and the base of the mixed layer,

$$
T_{\mathrm{ML}}\left(d_{\mathrm{ML}}-d_{\mathrm{WL}}\right)=\int_{-d_{\mathrm{ML}}}^{-d_{\mathrm{wL}}} T(z) d z .
$$

To complete the three-layer model, the thermocline layer is defined to be the layer at depths greater than $d_{\mathrm{ML}}$. It has a constant temperature $T_{\mathrm{TH}}$, which is taken to be the temperature at the level $5 \mathrm{~m}$ below the mixed layer depth,

$$
T_{\mathrm{TH}}=T\left(z=-d_{\mathrm{ML}}-5\right) .
$$

The thermocline layer is not used in the subsequent analysis but is included here for completeness, as it will be used in future modeling studies. 


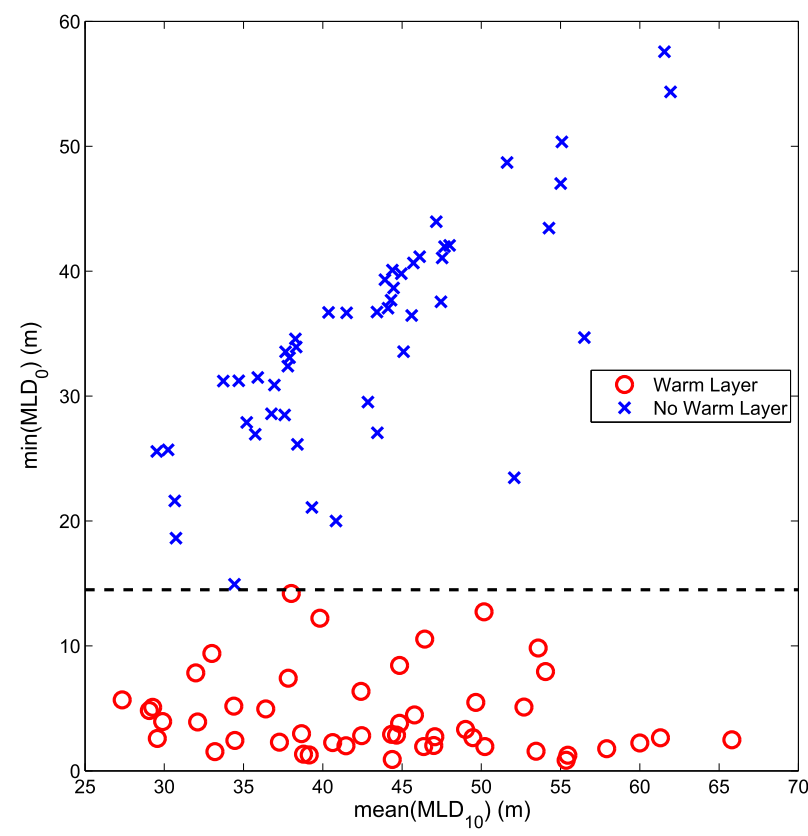

FIG. 7. Scatterplot of $\min \left(d_{\mathrm{MLsfc}}\right)$ against mean $\left(d_{\mathrm{ML}}\right)$. Days with a diurnal warm layer are shown by the red circles and days without a diurnal warm layer are shown by the blue crosses. The horizontal line at $\min \left(d_{\mathrm{MLsfc}}\right)=14.5$ divides the two regimes.

To quantify the effect of the diurnal warm layer, an alternative two-layer model is constructed where the diurnal warm layer and the mixed layer are combined, and the entire water column is mixed from the surface to the base of the mixed layer. This "super" mixed layer has temperature $T_{0}$, where

$$
T_{0} d_{\mathrm{ML}}=\int_{-d_{\mathrm{ML}}}^{0} T(z) d z .
$$

The second layer of this two-layer model is the thermocline layer, as before. This two-layer model would be appropriate for a numerical model that does not resolve the details of the diurnal warm layer development. It can be seen that

$$
T_{\mathrm{ML}} \leq T_{0} \leq T_{\mathrm{WL}}
$$

The increase in SST due to the existence of the warm layer is then

$$
T^{\prime}=T_{\mathrm{WL}}-T_{0} .
$$

Time series of these quantities are shown in Fig. 6c for the sample day, 3 December 2011. Before 0930 LST, the surface temperature is below the value of $T_{*}$ for that day. Hence, there is no warm layer, and $d_{\mathrm{WL}}=0, T_{\mathrm{WL}}=$ $T_{\mathrm{ML}}$, and $T^{\prime}=0$. At $0930 \mathrm{LST}$, the surface temperature is equal to $T_{*}$, and the warm layer begins to develop. Its depth $d_{\mathrm{WL}}$ increases approximately linearly, from $0 \mathrm{~m}$ at 0930 LST to $9.5 \mathrm{~m}$ at 2330 LST: that is, at a rate of approximately $0.7 \mathrm{~m} \mathrm{~h}^{-1}$. At $2330 \mathrm{LST}$, there is then rapid mixing of the water column, presumably because of nocturnal destabilization by cooling surface fluxes of infrared radiation and sensible and latent heat flux. The surface temperature rapidly decreases to below $T_{*}$, the warm layer vanishes, and $d_{\mathrm{WL}}=0$ again.

The temperature of the warm layer $T_{\mathrm{WL}}$ is equal to $T_{\mathrm{ML}}$ before $0930 \mathrm{LST}$, when the warm layer does not exist. It then increases rapidly to $29.0^{\circ} \mathrm{C}$ by $1000 \mathrm{LST}$ and then steadily to $29.12^{\circ} \mathrm{C}$ at $1600 \mathrm{LST}$. It then steadily decreases throughout the rest of the day. By contrast, the mixed layer temperature $T_{\mathrm{ML}}$ from the three-layer model and the super mixed layer temperature $T_{0}$ from the two-layer model both remain fairly constant throughout the day. Hence, $T^{\prime}$, the increase in SST due to the existence of the warm layer increases from $0^{\circ} \mathrm{C}$ at $0930 \mathrm{LST}$ to a maximum of $0.3^{\circ} \mathrm{C}$ at $1400-1600$ LST and then decreases to $0^{\circ} \mathrm{C}$ at $0030 \mathrm{LST}$ when the warm layer vanishes.

Although the diurnal warm layer is, by definition, a temperature structure, it may also have an effect on the near-surface salinity. At the glider location, there was a large freshwater input at the surface from precipitation (Fig. 2b). In the presence of mixing with the high-salinity water below, a steady-state salinity profile would result (Fig. 4). However, as the temperature stratification increases in the afternoon with the development of the diurnal warm layer, the mixing would be weakened. A transient fresh anomaly might be expected to develop at the surface at this time. Such a signal was sought, but data quality problems prevented any firm conclusions being made. This was because calculation of salinity from conductivity has a dependence on temperature. The long response time of the conductivity sensor compared with the temperature sensor, the glider crossing a high temperature gradient in the diurnal warm layer, and only the climb phase data being able to be used here all contributed to prevent salinity data of sufficient accuracy being produced in the upper few meters.

\section{Variability of diurnal warm layer formation}

The surface diurnal warm layer framework of section 4 is now extended from the sample day of 3 December 2011 (Fig. 6) to the whole study period, through a series of "stacked" diurnal cycles in Fig. 8. In these figures, each row represents the time series of a variable for a particular day, from 0000 UTC (approximately 0500 LST) to 2400 UTC (approximately 0500 LST on the next day). The rows are stacked above each other, so that the vertical axis represents time in (integer) days. There are 97 days in the study period (1 October 2011-5 January 

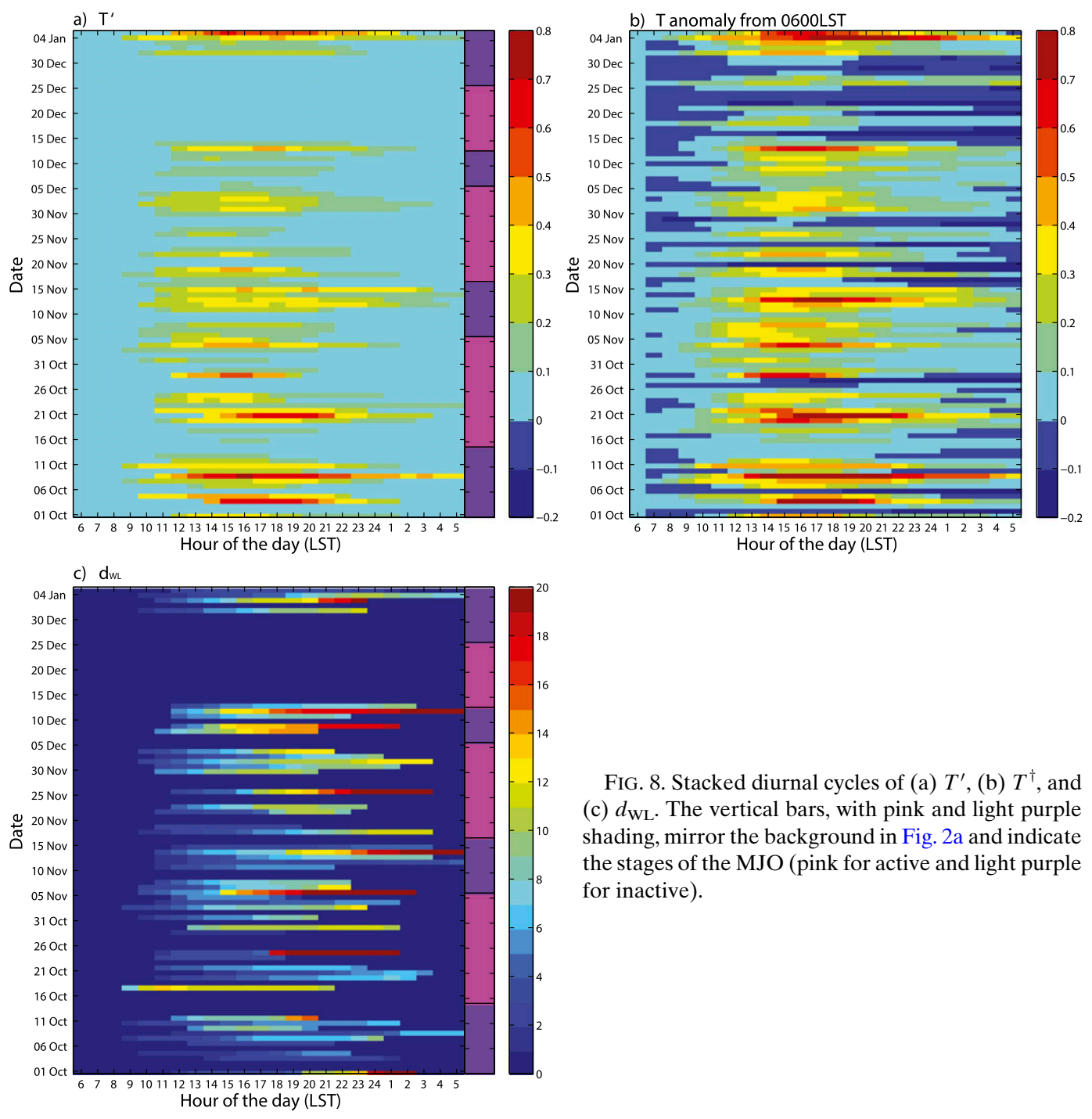

FIG. 8. Stacked diurnal cycles of (a) $T^{\prime}$, (b) $T^{\dagger}$, and (c) $d_{\mathrm{WL}}$. The vertical bars, with pink and light purple shading, mirror the background in Fig. 2a and indicate the stages of the MJO (pink for active and light purple for inactive).

2012), corresponding to 97 rows in the stacked diurnal cycles. Hence, the row corresponding to 3 December 2011 in the stacked diurnal cycle of $T^{\prime}$ (Fig. 8a) contains the same data as the time series of $T^{\prime}$ for this day in Fig. 6c.

Over the 97-day study period, there are clusters of days (e.g., 4-13 October 2011) where the diurnal warm layer develops, and $T^{\prime}$ regularly exceeds $0.4^{\circ} \mathrm{C}$ in the afternoon. There are other periods where there is no diurnal warm layer development, and $T^{\prime}=0$ throughout the day (e.g., 15-31 December 2011). The periods of surface diurnal warm layer development show a tendency to occur preferentially in the inactive stage of the MJO (light purple shading in vertical bar to the right of the stacked diurnal cycle in Fig. 8a). Conversely, periods with no diurnal warm layer development occur preferentially in the active stage of the MJO (pink shading in vertical bar).
However, this relationship between the occurrence of the diurnal warm layer and the state of the MJO is certainly not a perfect one. Convection and related conditions at a single geographical point (the glider location) are subject to large variability, as the planetary-scale MJO envelope is made up of contributions from multiple scales. This can clearly be seen in the time series of precipitation, wind speed, and shortwave radiation at the glider location (Fig. 2b). The tendency for wet, windy, and cloudy conditions in the active MJO stage and for dry, calm, and clear conditions in the inactive MJO stage can be seen. However, there is much day-to-day local variability. Hence, the analysis of the diurnal warm layer development in this limited dataset is made based on local conditions, rather than on the planetary-scale MJO state represented by the RMM index shown in Fig. 2a. 
TABLE 1. Contingency table of number of days when a diurnal warm layer formed or did not form, against the state of the MJO (active or inactive).

\begin{tabular}{lccc}
\hline & Warm layer & No warm layer & Total \\
\hline Active MJO & 23 & 31 & 54 \\
Inactive MJO & 25 & 18 & 43 \\
Totals & 48 & 49 & 97
\end{tabular}

The scatterplot in Fig. 7 and the stacked diurnal cycles in Fig. 8 show two clearly distinct regimes: diurnal warm layer days and nonwarm layer days. Using the criterion of Eq. (7), the population of 97 days in the study period is split in half, with 48 (49\%) warm layer days and 49 (51\%) nonwarm layer days.

The apparent relationship between diurnal warm layer formation and the state of the MJO can be tested statistically using a contingency table (Table 1). The background or unconditional probability, over all $N=97$ days, of warm layer formation on a particular given day is $p_{0}=$ $48 / 97=0.495$. The conditional observed probability of warm layer formation, given that the $\mathrm{MJO}$ is in its inactive stage, increases to $\hat{p}=25 / 43=0.581$. A test statistic

$$
Z=\frac{\hat{p}-p_{0}}{s_{\hat{p}}},
$$

where

$$
s_{\hat{p}}=\sqrt{\frac{p_{0}\left(1-p_{0}\right)}{N}}
$$

follows a Gaussian distribution with zero mean and unit standard deviation (e.g., Hall et al. 2001). Here, $Z=1.69$, which is above the critical value of $Z=1.64$ at the $90 \%$ significance level. Hence, the null hypothesis, that the probability of a diurnal warm layer forming is independent of the state of the MJO, is rejected at the $90 \%$ level.

The calculation of $T^{\prime}$ [Eqs. (3)-(12)] is rather involved. To verify that the existence of the surface diurnal warm layer is not an artifact of this processing, a stacked diurnal cycle is constructed for a simpler measure of the diurnal temperature variation

$$
T^{\dagger}(t)=T(t)-T_{06} .
$$

Here, the surface $(0.5 \mathrm{~m})$ temperature at any particular time is expressed as an anomaly $T^{\dagger}$ from its value at sunrise (0600 LST) on that same day. Hence, all the anomalies in the first column of the stacked diurnal cycle of $T^{\dagger}$ (Fig. 8b), at 0600 LST, are zero by definition. The broad pattern and variability of the $T^{\prime}$ anomalies are reproduced, confirming that the analysis is not sensitive to the detailed processing.
The stacked diurnal cycle of the depth of the diurnal warm layer $\left(d_{\mathrm{WL}}\right.$; Fig. $\left.8 \mathrm{c}\right)$ shows coherent growth in the layer depth throughout the days when a warm layer is found. Typical maximum values lie between 5 and $20 \mathrm{~m}$. There is also considerable variability in the duration of the warm layer, with the terminal mixing and disappearance of the layer generally occurring between sunset (1800 LST) and the early hours of the next morning.

\section{Structure of diurnal warm layer}

\section{a. Exponential profile}

The mean diurnal cycle averaged over all the warm layer days (shading and line contours in Fig. 9a) shows a clear development of a diurnal warm layer, as expected. For this mean diurnal cycle, $T_{06}=28.94^{\circ} \mathrm{C}$ and $T_{\max }=29.36^{\circ} \mathrm{C}$. Hence, the isotherm that defines the warm layer is $T_{*}=$ $29.05^{\circ} \mathrm{C}$ [Eq. (3)]. Temperatures above $T_{*}$ are shaded red in Fig. 9a. This mean diurnal warm layer starts at 0900 LST, reaches a maximum depth of $d_{\mathrm{WL}}=8 \mathrm{~m}$ at $1900 \mathrm{LST}$, and finally disappears at 0100 LST the following morning.

Note that the surface temperature minimum at sunrise $T_{06}$ is actually lower than the temperature immediately below. Hence, there is a temperature inversion at the surface. However, because salinity is also a minimum at the surface (Fig. 4), the density increases monotonically with depth and the profile remains statically stable.

At all depths within the diurnal warm layer, the temperature minimum and maximum are separated by approximately $12 \mathrm{~h}$. Hence, the diurnal harmonic (i.e., a shifted cosine wave with a period of exactly $24 \mathrm{~h}$ ) is a good approximation to the full diurnal cycle. At each level, the diurnal harmonic of the mean diurnal cycle of temperature is calculated. The semidiurnal and higher harmonics were also calculated but found to be very weak. The amplitude of the diurnal harmonic of temperature decreases monotonically with depth $d$ down to $20 \mathrm{~m}$ (thin black line with dots in Fig. 9a). The phase of the diurnal harmonic (expressed as time of maximum temperature) is shown by the thick line in Fig. 9a. It increases slowly with depth, from 1600 LST at the surface to 1800 LST at $13 \mathrm{~m}$, and then decreases slowly down to $20 \mathrm{~m}$. Below this level, sampling variability due to gravity waves and their vertical movement of the thermocline masks the structure of the diurnal cycle.

The observed amplitude $T_{\mathrm{dh}}$ of the diurnal harmonic is very well modeled by an exponential function of the form

$$
T_{\mathrm{dh}}(d)=T_{\mathrm{dh} 0} e^{-d / H}+\epsilon,
$$

where $T_{\mathrm{dh} 0}=0.22^{\circ} \mathrm{C}$ is the (extrapolated) amplitude of the diurnal harmonic at the surface $(z=0$; i.e., the SST), the scale depth is $H=4.2 \mathrm{~m}$, and $\epsilon=0.004^{\circ} \mathrm{C}$ is a residual 


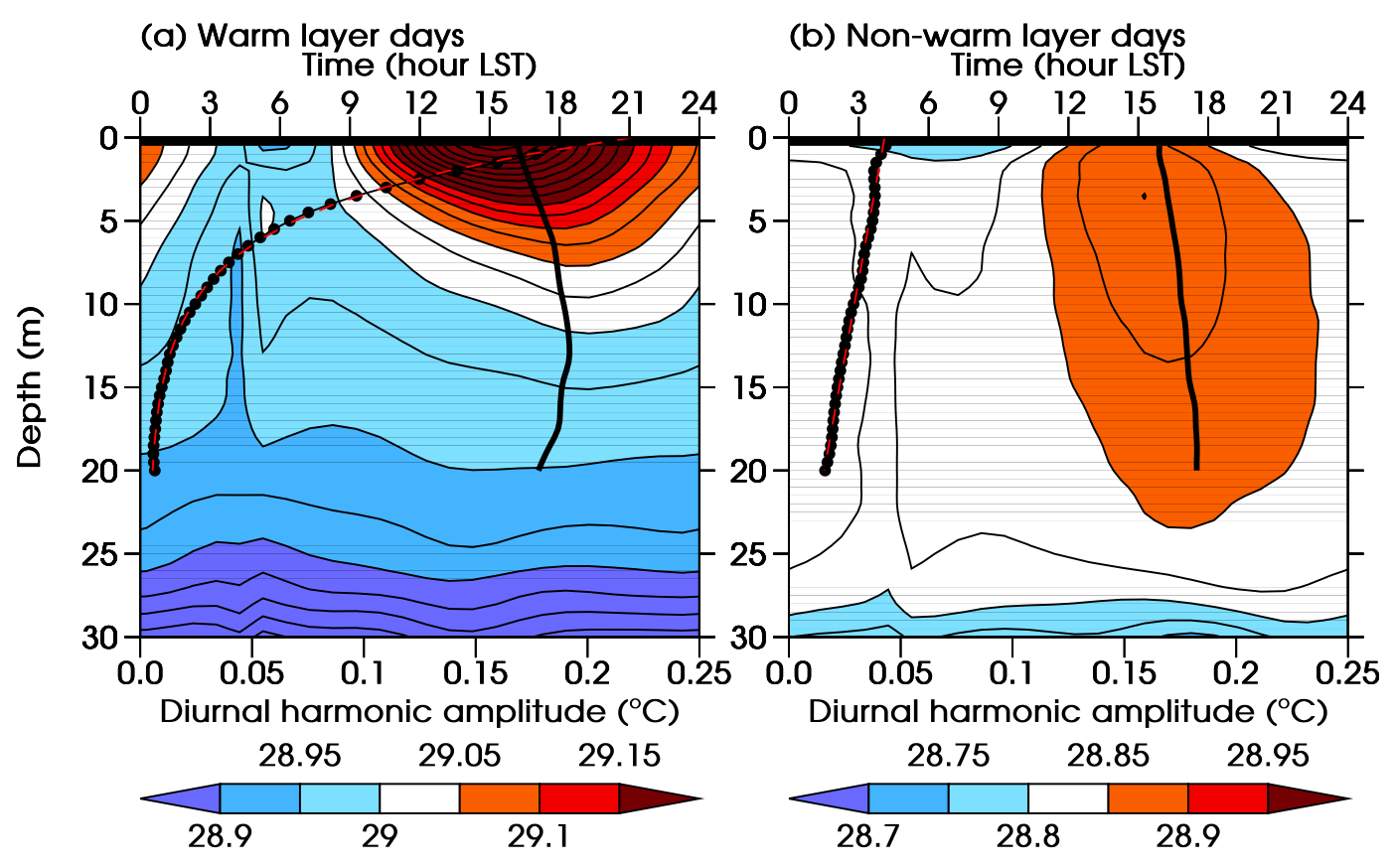

FIG. 9. Mean diurnal cycle of temperature during (a) warm layer days and (b) nonwarm layer days. Shading interval is $0.05^{\circ} \mathrm{C}$ in both panels; see legends for shading intervals. Line contour interval is $0.025^{\circ} \mathrm{C}$. The profile of the diurnal harmonic amplitude is shown by the black dots in each panel; see bottom axis for scaling. The dashed red line shows the best-fit exponential function in (a) and linear function in (b). The profile of the diurnal harmonic phase (time of maximum temperature) is shown by the thick black line in both panels.

constant term. The values of these parameters were determined by least squares regression of Eq. (16) onto the observations, and the modeled curve is shown by the dotted red line in Fig. 9a. The root-mean-square error is $0.0017^{\circ} \mathrm{C}$. Hence, the diurnal harmonic of temperature can be modeled as

$$
T(d, t)=T_{\mathrm{ref}}(d)+T_{\mathrm{dh} 0} e^{-d / H} \cos \left[\frac{2 \pi}{24}\left(t-16-\frac{2 d}{13}\right)\right],
$$

where $t$ is time (hour of day local solar time) and $T_{\text {ref }}(d)$ is the background or reference temperature profile.

This exceptionally close agreement between the observed profile of the temperature diurnal harmonic and an exponential function is consistent with the theoretical and observed profiles of solar radiation in seawater. The downward solar radiation flux in seawater, which is responsible for the diurnal warming, also follows an exponential profile, through the Beer-Lambert law for absorption.

In fact, the absorption of solar radiation might be expected to follow a double exponential function with two scale depths. One corresponds to the absorption by the red part of the solar spectrum and has a scale depth in the range 0.35-1.4 m (Jerlov 1968; Paulson and Simpson 1977; Mobley 1994; Ohlmann et al. 1998). The other corresponds to absorption of blue-green light, with a scale depth in the range $7.9-23 \mathrm{~m}$. The single scale depth of $H=4.2 \mathrm{~m}$ found here is between these values and corresponds to a mean value for absorption across the whole solar spectrum. However, when a double exponential function was fitted to the observational data, no improvement was found over the single exponential function of Eq. (16). The two scale depths produced were both very close to $4.2 \mathrm{~m}$.

\section{b. Effect of chlorophyll on the diurnal warm layer}

The range of scale depths from previous studies (e.g., Paulson and Simpson 1977) is attributable to different water "types." These have different concentrations of inorganic and organic particles that absorb solar radiation in addition to the absorption by water molecules. Limited measurements of chlorophyll concentration were made by the Seaglider, using a Wetlabs EcoPuck measuring chlorophyll fluorescence. High chlorophyll concentrations are an indication of high phytoplankton abundance and therefore potentially stronger solar absorption of solar radiation and a lower scale depth in Eq. (16).

There were 14 warm layer days when chlorophyll data were available. These separated into two clear regimes. There were 10 days in a low chlorophyll regime, where the mean $0-10-\mathrm{m}$ chlorophyll concentration was in the range $1.1-5.8 \mathrm{mg} \mathrm{m}^{-3}$, with a mean of $3.3 \mathrm{mg} \mathrm{m}^{-3}$. The 

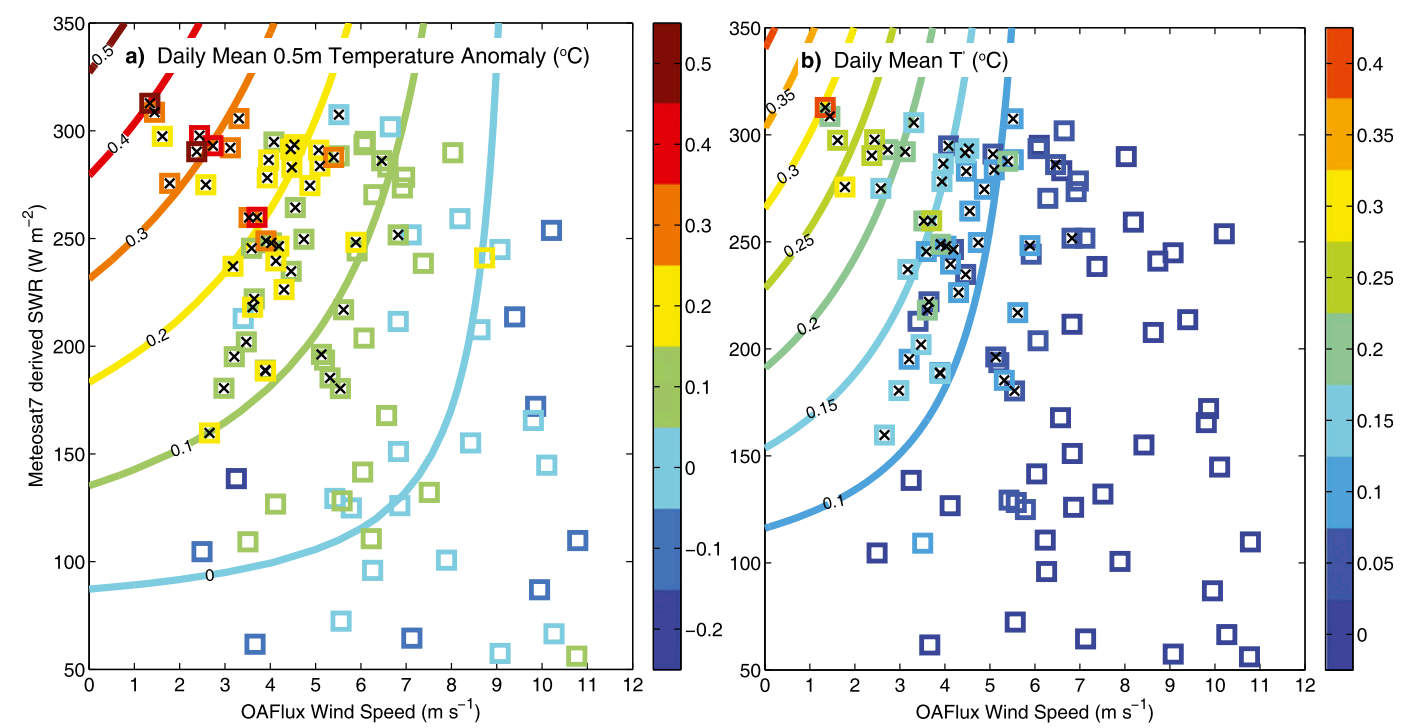

FIG. 10. (a) Scatterplot of daily-mean OAFlux wind speed vs Meteosat-7-derived SWR, colored by $T^{\dagger}$. Color contours show the best-fit regression lines of $T_{\text {predicted }}^{\dagger}$ (b) As in (a), but for $T^{\prime}$. The regression lines in (b) are calculated only using data from warm layer days. Points marked with a cross are days when a warm layer developed.

remaining 4 days were in a high chlorophyll regime, in the range $14.4-21.7 \mathrm{mg} \mathrm{m}^{-3}$, with a mean of $18.8 \mathrm{mg} \mathrm{m}^{-3}$. The mean diurnal cycle was calculated separately for each of these two regimes. Despite the low sample sizes, a well-defined diurnal warm layer with an exponential temperature profile developed in each regime.

Recall that the scale depth was $H=4.2 \mathrm{~m}$ when calculated over all 48 warm layer days. The low chlorophyll regime had a higher scale depth of $H=4.7 \pm 0.1 \mathrm{~m}$, corresponding to weaker absorption. The high chlorophyll regime had a lower scale depth of $H=4.0 \pm 0.3 \mathrm{~m}$, corresponding to stronger absorption. Hence, even with the limited measurements available, chlorophyll variability has a clear and significant effect on the depth of the diurnal warm layer and then potentially on the rectification of SST by the diurnal cycle.

A detailed analysis of the Seaglider-measured chlorophyll during CINDY/DYNAMO is presented in Webber et al. (2014). They showed that the variability in chlorophyll was controlled by Ekman pumping by the local surface winds and propagation of oceanic equatorial Rossby waves, as part of the dynamical ocean-atmosphere MJO system (Webber et al. 2010).

\section{A predictive model for diurnal warm layer formation}

The diurnal cycle of temperature at the ocean surface is controlled by two competing processes. The diurnal cycle of surface shortwave radiation flux heats the surface, stabilizes the water column, and forces a strong diurnal cycle.
Wind-driven mixing mixes up cold water from below and weakens the diurnal cycle. In this section, these two effects are quantified, and a predictive model for the strength of the diurnal cycle is developed, based on the daily-mean surface shortwave radiation flux and wind speed.

Daily-mean values of the diurnal temperature change are calculated, along with daily-mean values of the Meteosat-7-derived surface shortwave radiation flux (SWR) at the glider location and surface wind speed $V$ from the OAFlux dataset (Yu et al. 2008).

First, the dependence of the simple measure of diurnal temperature anomaly from sunrise $T^{\dagger}$, on SWR and $V$, is examined. A scatterplot of $T^{\dagger}$ against SWR and $V$, colored by the value of $T^{\dagger}$ (Fig. 10a), shows a clear dependence. High values of $T^{\dagger}$ occur on days with high SWR and low $V$. Days on which a diurnal warm layer formed, according to the criterion of Eq. (7), are indicated by an additional cross. These occur exclusively on days with high shortwave flux and low wind speed. A predictive model is calculated by nonlinear regression, such that

$$
T_{\text {predicted }}^{\dagger}=\alpha_{1} \mathrm{SWR} V+\alpha_{2} \mathrm{SWR}+\alpha_{3} V+\alpha_{4},
$$

where $\alpha_{1}=-2.16 \times 10^{-4}, \alpha_{2}=0.00208, \alpha_{3}=0.0152$, and $\alpha_{4}=-0.182$, with $T_{\text {predicted }}^{\dagger}$ in degrees Celsius, SWR in watts per square meter, and $V$ in meters per second. Contours of $T_{\text {predicted }}^{\dagger}$ are overlaid in Fig. 10a and fit the data well.

A more physically useful measure of the diurnal temperature change is $T^{\prime}$, the change in SST due to the existence of the diurnal warm layer [Eq. (12)]. Values of $T^{\prime}$ 


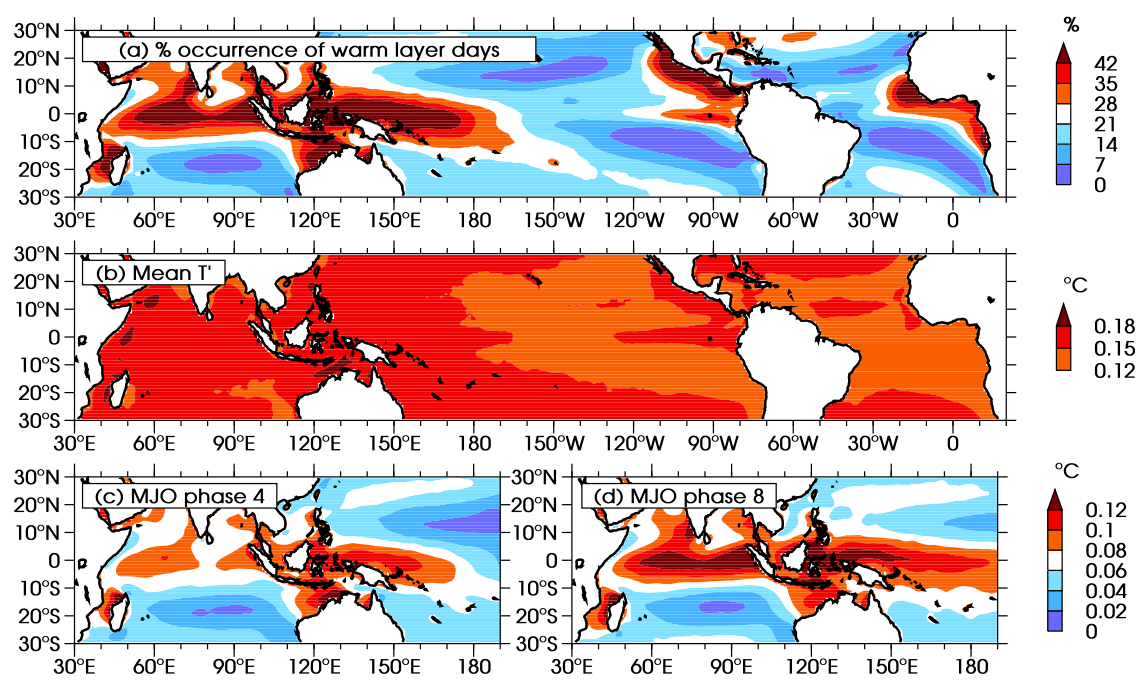

FIG. 11. (a) Percentage of days when a diurnal warm layer is predicted to occur. (b) Mean predicted $T^{\prime}$ on those warm layer days. (c) Mean predicted $T^{\prime}$ for all days in MJO phase 4. (d) As in (c), but for MJO phase 8 .

show a similar relationship with SWR and $V$ (Fig. 10b). As $T^{\prime}$ is only meaningful on days when a diurnal warm layer forms, the predictive model for $T^{\prime}$ is calculated only using data from these days (crosses in Fig. 10b). The model is

$$
T_{\text {predicted }}^{\prime}=\beta_{1} \mathrm{SWR} V+\beta_{2} \mathrm{SWR}+\beta_{3} V+\beta_{4},
$$

with $\beta_{1}=-0.000208, \beta_{2}=0.00130, \beta_{3}=0.0159$, and $\beta_{4}=$ -0.0556 . Contours of $T_{\text {predicted }}^{\prime}$ are overlain in Fig. $10 \mathrm{~b}$. The predictive Eq. (19) for $T^{\prime}$ asymptotes to a constant value of $T_{\text {predicted }}^{\prime}=\beta_{4}-\beta_{2} \beta_{3} / \beta_{1}=0.044^{\circ} \mathrm{C} \approx 0$, at SWR $=-\beta_{3} / \beta_{1}=76 \mathrm{Wm}^{-2}$ and also at $V=-\beta_{2} / \beta_{1}=$ $6.2 \mathrm{~m} \mathrm{~s}^{-1}$. These are nonlinear cutoffs, giving the minimum value of SWR and maximum value of $V$ under which a diurnal warm layer can form. In practice, it can be seen that diurnal warm layer days (crosses in Fig. 10b) occur almost exclusively on days when

$$
T_{\text {predicted }}^{\prime} \geq 0.1^{\circ} \mathrm{C} \text {. }
$$

Assuming that this locally derived relationship holds approximately over the tropics, the importance of diurnal warm layer development can now be assessed across the tropical ocean basins. Daily maps of predicted warm layer occurrence, using Eq. (20), are calculated from daily maps of TropFlux surface shortwave radiation flux and wind speed, from 1 January 1979 to 31 December 2011. A diurnal warm layer is predicted to occur on over $25 \%$ of days over the tropical warm pool region of the Indian Ocean and western Pacific (Fig. 11a). Other regions of importance are the far eastern Pacific and the eastern Atlantic. The predicted mean excess of SST $T^{\prime}$ over nearly all the tropical oceans, when a warm layer develops, is in the range $0.12^{\circ}-0.18^{\circ} \mathrm{C}$ (Fig. 11b). These results are broadly consistent with Bellenger and Duvel (2009), who defined the diurnal warm layer with a different metric.

In section 5, it was shown that warm layer days at the glider location occurred preferentially in the inactive stage of the MJO (RMM phases 5-8) over the Indian Ocean. This deduction was based on data measured at a single location over a relatively short time period. The generality of this observation can now be tested using the global maps of predicted $T^{\prime}$. The mean predicted $T^{\prime}$ averaged over all, not just warm layer, days in MJO phase 4 is approximately $0.08^{\circ} \mathrm{C}$ across the equatorial Indian Ocean (Fig. 11c). Hence, even in the active stage of the MJO, when the effects of the diurnal cycle are at their weakest, a model that cannot resolve these processes would underestimate the SST by approximately $0.08^{\circ} \mathrm{C}$. During the opposite part of the MJO cycle (phase 8 , in the inactive stage), this error would be larger, with mean $T^{\prime}$ values over $0.12^{\circ} \mathrm{C}$ over the equatorial Indian Ocean (Fig. 11d).

\section{Diurnal cycle rectification: Implied anomalous surface fluxes}

The development of the diurnal warm layer increases the SST by an amount $T^{\prime}$, compared with the situation if the warm layer did not exist. Alternatively, the negative of $T^{\prime}$ is the SST error that a model would incur if it could not resolve these processes. Instantaneous peak values of $T^{\prime}$ in the afternoon can reach $1^{\circ} \mathrm{C}$ (Fig. $8 \mathrm{a}$ ), and daily-mean 
values are in the range $0.1^{\circ}-0.3^{\circ} \mathrm{C}$ (Figs. 10b, 11b-d). The existence and strength of the diurnal warm layer depends on the surface fluxes of shortwave radiation and momentum (through the wind speed). However, the changes in SST by the increment $T^{\prime}$ will have a feedback onto the surface fluxes and a subsequent effect on ocean-atmosphere interaction. In this section, the effect of $T^{\prime}$ on the surface fluxes is quantified. A daily-mean value of $T^{\prime}=0.2^{\circ} \mathrm{C}$ will be used to produce numerical values of anomalous surface fluxes.

The surface fluxes are linearized about the mean state to calculate the perturbation fluxes due to the surface temperature anomaly $T^{\prime}$. The details of the individual fluxes of longwave radiation, latent and sensible heat are described in appendix B. The total perturbation flux is

$$
\begin{aligned}
Q^{\prime} & =Q_{\mathrm{LW}}^{\prime}+Q_{L}^{\prime}+Q_{S}^{\prime} \\
& =\left[4 \sigma T_{b}^{3}+\left(\frac{L^{2} \epsilon e_{s_{0}}}{R R_{w} T_{b}^{3}}+\rho_{a} c_{p}\right) c_{E} V\right] T^{\prime} \\
& =(6.3+13+3.5) T^{\prime} \approx 23 T^{\prime} \\
& \approx 4 \mathrm{~W} \mathrm{~m}^{-2} .
\end{aligned}
$$

This is the extra cooling surface flux that occurs due to the existence of the diurnal warm layer. Models that do not simulate these processes would have an SST that is too cool and therefore an erroneous downward surface flux of approximately $4 \mathrm{~W} \mathrm{~m}^{-2}$. This represents a physical process by which heating on longer time scales is rectified by the diurnal cycle of solar heating.

An estimate of the range of the perturbation flux can be made. From Eq. (21), the parameters that significantly vary are $T^{\prime}$, as explicitly stated, and also $V$, the surface wind speed. The range of these parameters over the diurnal warm layer days can be estimated from Fig. 10b as $T^{\prime} \approx 0.05^{\circ}-0.35^{\circ} \mathrm{C}$ and $V \approx 1.5-7 \mathrm{~m} \mathrm{~s}^{-1}$. However, they do not vary independently. On low wind speed days, $T^{\prime}$ is high and vice versa. Hence, their contributions to the variation in $Q^{\prime}$ partially cancel. For example, a very low wind speed day has $V=1.5 \mathrm{~m} \mathrm{~s}^{-1}$ and $T^{\prime}=0.35^{\circ} \mathrm{C}$, giving $Q^{\prime} \approx 5 \mathrm{~W} \mathrm{~m}^{-2}$. A high wind speed day has $V=7 \mathrm{~m} \mathrm{~s}^{-1}$ and $T^{\prime}=0.05^{\circ} \mathrm{C}$, giving $Q^{\prime} \approx 2 \mathrm{~W} \mathrm{~m}^{-2}$. Hence, the range of the expected perturbation flux on diurnal warm layer days is $Q^{\prime} \approx 2-5 \mathrm{~W} \mathrm{~m}^{-2}$.

There will also be an error in the calculated value of $T^{\prime}$ resulting from the optimally interpolated data only being available up to a level of $z=z_{e}=-0.5 \mathrm{~m}$ and not all the way to the surface at $z=0$. Assuming that the actual temperature profile follows the idealized exponential profile [Eq. (16)], it can be shown, after some algebra, that the error incurred in $T^{\prime}$ is

$$
\Delta T^{\prime}=T_{\mathrm{dh} 0} \frac{\alpha-1}{\ln \alpha}\left(e^{z_{e} / H}-1\right) \approx 0.01^{\circ} \mathrm{C} \text { or an } \sim 5 \% \text { error } .
$$

This is negligible compared to the other assumptions made and the day-to-day range of $T^{\prime}$.

\section{Residual diurnal cycle in absence of diurnal warm layer}

A surface diurnal warm layer developed on 48 of the 97 days in the study period. These days were characterized by high solar radiation flux and low wind speed. However, although a surface diurnal warm layer did not develop on the remaining 49 days, there was still a residual diurnal cycle, which exhibits qualitatively very different behavior to the surface diurnal warm layer (Fig. 9b). By design, the residual diurnal cycle is much weaker with a range of only $0.08^{\circ} \mathrm{C}$ in the surface temperature, compared with a range of $0.44^{\circ} \mathrm{C}$ for the warm layer days. On the nonwarm layer days, the water column is also much cooler overall, with a mean surface temperature of $28.82^{\circ} \mathrm{C}$, compared with $29.14^{\circ} \mathrm{C}$ for the warm layer days. This is consistent with the diurnal warm layer preferentially occurring in the inactive stage of the MJO, when the SST is increasing to its maximum value.

However, in addition to these expected differences, there is also a clear qualitative difference in the spatial structure of the diurnal cycle of temperature. The much weaker surface warming in the nonwarm layer days is spread out over a much larger depth than in the warm layer days. A linear function provides a more appropriate fit (than an exponential function) to the observed structure (black line with dots in Fig. 9b), where

$$
T_{\mathrm{dh}}=T_{\mathrm{dh} 0}-\gamma d,
$$

with the surface amplitude $T_{\mathrm{dh} 0}=0.04^{\circ} \mathrm{C}$ and the gradient $\gamma=0.0014^{\circ} \mathrm{C} \mathrm{m}^{-1}$. By extrapolation, the amplitude of the diurnal harmonic becomes zero at depth $D$, where

$$
D=\frac{T_{\mathrm{dh} 0}}{\gamma}=32 \mathrm{~m}
$$

The linear profile might be expected. Surface heating is accomplished through the absorption of solar radiation with an exponential profile in the upper few meters. In low wind conditions, with weak mixing, this leads to formation of a diurnal warm layer, with a similar exponential temperature profile. However, in high wind conditions, this warm surface layer will be mixed down into the cooler water below. The linear profile is then a steady-state solution of the (eddy) diffusion equation, with boundary conditions of constant temperature at the surface and the base of the diurnal layer (at $D \approx 30 \mathrm{~m}$ here). Note that the temperature gradient in this linear diurnal layer is very weak and is only detectable because of the high-quality, high-resolution measurements available from the glider. 
As wind speed increases, this already very weak vertical temperature gradient would be expected to decrease further, tending toward isothermal conditions, with a weaker vertical temperature gradient $\gamma$ and a lower surface amplitude $T_{\mathrm{dh} 0}$. The stronger mixing would also extend over a deeper layer; hence, the depth of the linear diurnal layer might be expected to increase with wind speed. To test this hypothesis, the 49 nonwarm layer days were ordered by the strength of the OAFlux dailymean wind speeds at the glider location. They were then stratified into three wind regimes of approximately equal sample size $(16,16$, and 17 days, respectively). In the low wind speed regime, the wind speed was in the range 2.5$6.1 \mathrm{~m} \mathrm{~s}^{-1}$, with a mean of $\bar{V}=4.9 \mathrm{~m} \mathrm{~s}^{-1}$. The medium regime had winds of $6.1-7.9 \mathrm{~m} \mathrm{~s}^{-1}$, with a mean of $\bar{V}=$ $6.8 \mathrm{~m} \mathrm{~s}^{-1}$. The high regime consisted of all days with winds above $7.9 \mathrm{~m} \mathrm{~s}^{-1}$, with a mean of $\bar{V}=9.4 \mathrm{~m} \mathrm{~s}^{-1}$.

A mean diurnal cycle was constructed separately for each of the three regimes. A clear linear temperature profile was reproduced in each regime. As hypothesized, the linear temperature gradient did monotonically decrease with wind speed (Fig. 12, black solid line), by a factor of 4 from $\gamma=0.0020^{\circ} \mathrm{Cm}^{-1}$ at $\bar{V}=4.9 \mathrm{~m} \mathrm{~s}^{-1}$ to $\gamma=0.0005^{\circ} \mathrm{Cm}^{-1}$ at $\bar{V}=9.4 \mathrm{~m} \mathrm{~s}^{-1}$. The surface amplitude was approximately constant at $T_{\mathrm{dh} 0} \approx 0.05^{\circ} \mathrm{C}$ in the low and medium wind speed regimes but then decreased to $T_{\mathrm{dh} 0}=0.027^{\circ} \mathrm{C}$ in the high wind regime (Fig. 12, blue dotted line). The depth of the linear diurnal layer increased consistently with wind speed, from $D=25 \mathrm{~m}$ at $\bar{V}=4.9 \mathrm{~m} \mathrm{~s}^{-1}$ to $D=55 \mathrm{~m}$ at $\bar{V}=9.4 \mathrm{~m} \mathrm{~s}^{-1}$.

\section{Summary and conclusions}

The time-developing structure of the diurnal warm layer in the equatorial Indian Ocean was diagnosed, using high-resolution measurements from a Seaglider during the CINDY/DYNAMO field experiment. Two distinct regimes were found, summarized in the schematic in Fig. 13.

On half of the days in the study period, a diurnal warm layer developed (Fig. 13a). It was characterized by a temperature structure with a surface maximum that peaked in the midafternoon at 1600 LST. The temperature anomaly decayed exponentially with depth over a scale depth of $4-5 \mathrm{~m}$, depending on chlorophyll concentration. This is consistent with heating by absorption of solar radiation. In the late afternoon and after sunset, the cooling fluxes of longwave radiation and latent and sensible heat fluxes took over and the diurnal warm layer decayed. Eventually, just before sunrise, the surface cooling was enough to destabilize the water column, which rapidly overturned, creating a deeper isothermal mixed layer. Because the solar heating was effectively trapped in the shallow diurnal

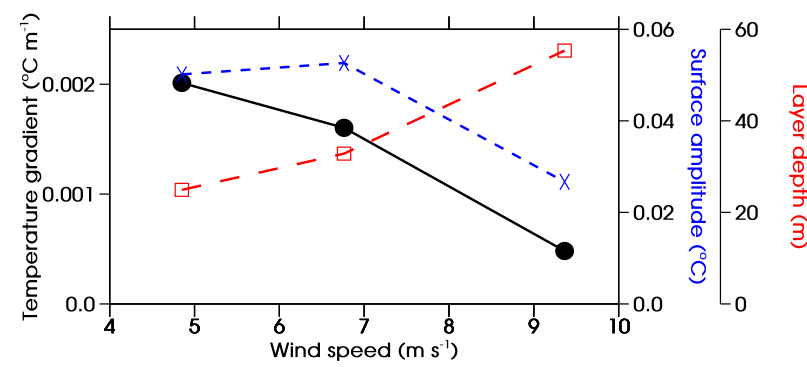

FIG. 12. Dependence of linear temperature profile parameters on wind speed for the residual diurnal cycle on nonwarm layer days: vertical temperature gradient $\gamma$ (black solid line); surface amplitude $T_{\mathrm{dh} 0}$ (blue dotted line); and layer depth $D$ (red dashed line).

warm layer during the day, the daily-mean SST is higher than it would be in the absence of the diurnal warm layer. Hence, the SST on longer time scales, including the climatological mean, should be rectified by the diurnal cycle. This rectification is quantified by a simple model. The mean effective SST anomaly due to the existence of the diurnal warm layer is $T^{\prime} \approx 0.2^{\circ} \mathrm{C}$.

On the remaining half of the days, a diurnal warm layer did not develop. Instead, a much weaker residual diurnal cycle was observed, whose amplitude showed a linear decrease with depth down to approximately 25$50 \mathrm{~m}$ (Fig. 13b), dependent on wind speed. This is consistent with control by vertical mixing.

The days when a diurnal warm layer did develop were characterized by high values of solar radiation flux (above approximately $80 \mathrm{~W} \mathrm{~m}^{-2}$ ) and low wind speeds (below approximately $6 \mathrm{~m} \mathrm{~s}^{-1}$ ). Conversely, the days with no diurnal warm layer had low solar radiation and high wind speed.

A predictive model for the existence and strength of the diurnal warm layer was developed, using the TropFlux gridded solar radiation flux and wind speed products. Surface diurnal warm layers are predicted to occur on over $30 \%$ of days across the warm pool region and over the tropical eastern Pacific and eastern Atlantic. At first, this might seem surprising, as these are regions of maximum mean precipitation and cloudiness, as well as minimum mean solar radiation flux, compared with other locations at the same latitude. However, there is much temporal variability in precipitation and cloud cover resulting from the multiscale nature of tropical convection. On days when cloud cover is absent, the wind speed is low enough to allow a surface diurnal warm layer to form. This variability is linked with the MJO, with a higher proportion of diurnal warm layer days within the convectively suppressed phase of the MJO, compared to the convectively active phase.

Conversely, regions of high mean solar radiation flux, such as the relatively cloud-free central equatorial and 
(a) Diurnal warm layer

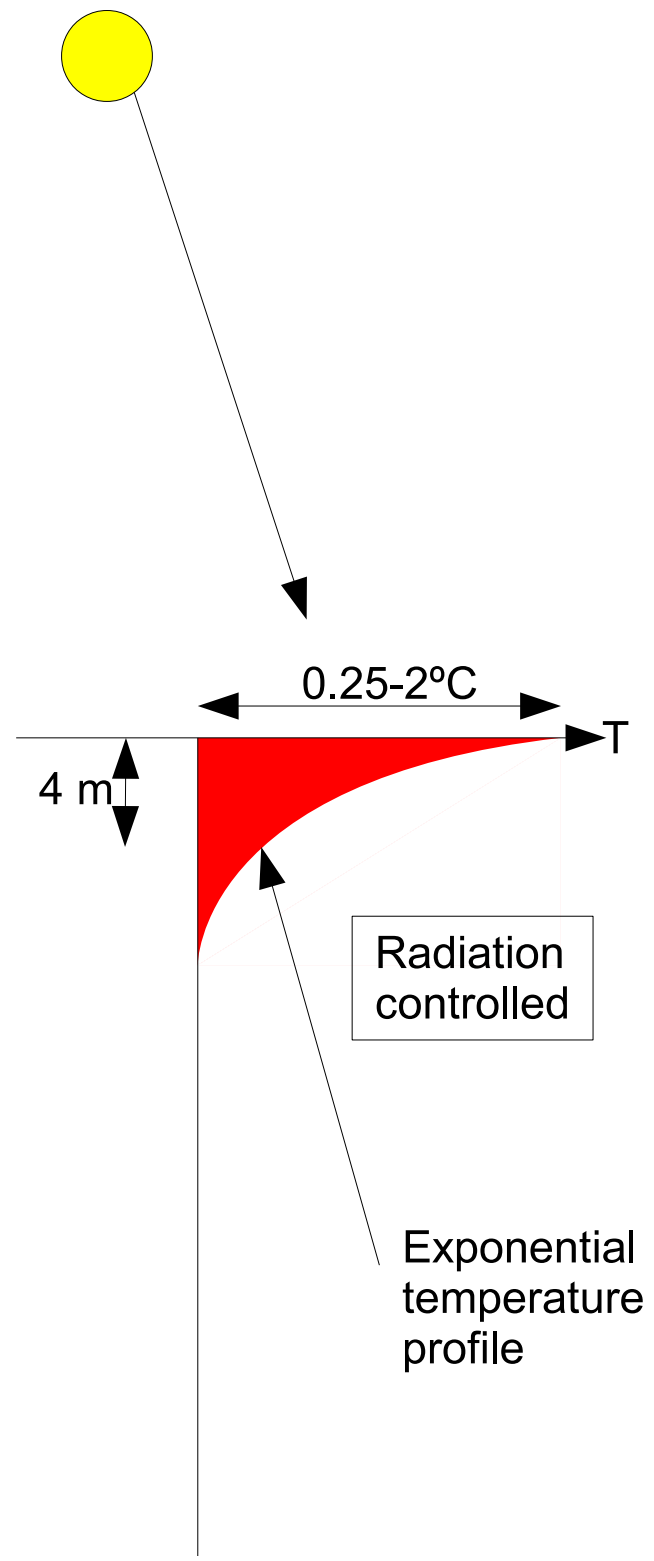

(b) Residual diurnal cycle

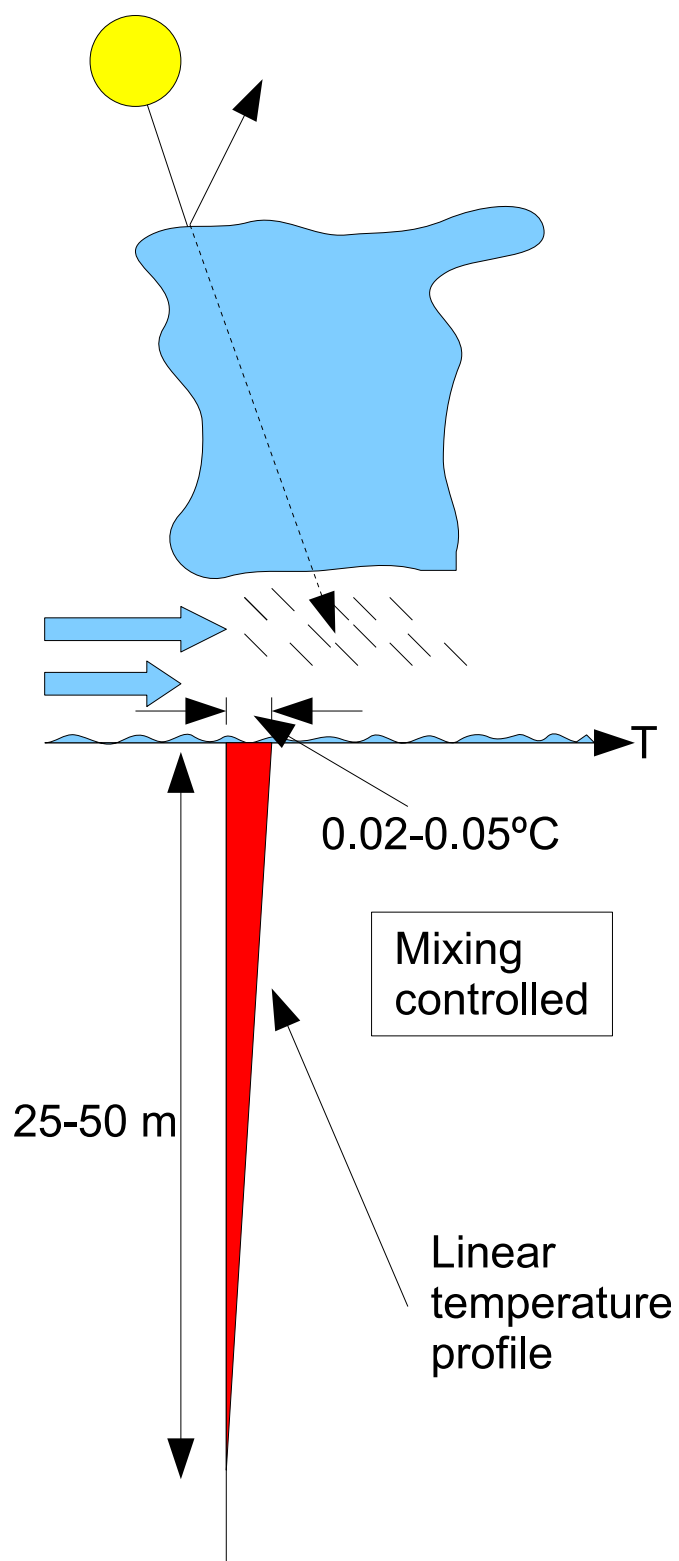

FIG. 13. Schematic diagram of processes leading to the (a) diurnal warm layer and (b) residual diurnal cycle.

subtropical Pacific, had a much lower proportion of diurnal warm layer days. This is due to the consistently high wind speeds in these trade wind regimes.

The daily-mean SST anomaly due to the existence of the diurnal warm layer will drive anomalous fluxes of longwave radiation and latent and sensible heat. The flux equations were linearized about the mean state to quantify this. The anomalous flux is on the order of $4 \mathrm{Wm}^{-2}$ upward, cooling the ocean and warming the atmosphere. A coupled ocean-atmosphere model that does not resolve the diurnal warm layer would incur the negative of this flux anomaly as an error: that is, an erroneous flux of $4 \mathrm{~W} \mathrm{~m}^{-2}$ downward, warming the ocean and cooling the atmosphere.

A flux anomaly, or error, of this magnitude is significant. For example, it is comparable to the differences between surface flux estimates from various reanalysisbased climatologies for the Indian Ocean at these latitudes (Schott et al. 2009). On intraseasonal time scales, surface flux anomalies drive the ocean-atmosphere interactions with the MJO. During the inactive stage of the MJO, these anomalies are on the order of $20 \mathrm{~W} \mathrm{~m}^{-2}$ 
and are downward, warming the ocean ahead of the MJO convection (Shinoda et al. 1998; Woolnough et al. 2000). The flux anomaly due to the diurnal warm layer is upward, cooling the ocean, and will act as a weak negative feedback on the coupled ocean-atmosphere component of the MJO.

Future modeling studies will investigate the SST and surface flux contributions from the diurnal warm layer, and the errors incurred when the processes are not resolved. These modeling studies, as well as the observational analysis here, can then feed into the development of a parameterization scheme for the effect of the diurnal warm layer in coarse-resolution coupled oceanatmosphere models.

Acknowledgments. This work was partially funded by the European Union 7th Framework Programme (FP7 2007-2013) under Grant Agreement 284321 GROOM Project. DB was supported partially by a POGO-SCOR training fellowship and partially through an Office of Naval Research grant managed by Dan Eluterio, Scott Harper, and ONR Global. We thank Ren-Chieh Lien and the other scientists and crew of the R/V Roger Revelle for logistical support in deploying and retrieving the Seaglider during CINDY/DYNAMO. The interpolated OLR, NCEP reanalysis, and NOAA OISST version 2 data were provided by the NOAA/OAR/ ESRL/PSD, Boulder, Colorado, from their website (at http://www.cdc.noaa.gov/). The TRMM 3B42 data were obtained from NASA Goddard DAAC, from their website (at http://disc.gsfc.nasa.gov/services/opendap/). The Wheeler and Hendon (2004) MJO index data were obtained from the Centre for Australian Weather and Climate Research from their website (at http://www. cawcr.gov.au/staff/mwheeler/maproom/). The OAFlux data were provided by the WHOI OAFlux project (http://oaflux.whoi.edu) funded by the NOAA Climate Observations and Monitoring (COM) program. The TropFlux data are produced under a collaboration between Laboratoire d'Océanographie: Expérimentation et Approches Numériques (LOCEAN) from Institut Pierre Simon Laplace (IPSL, Paris, France) and National Institute of Oceanography/CSIR (NIO, Goa, India) and supported by Institut de Recherche pour le Développement (IRD, France). TropFlux relies on data provided by the ECMWF Interim Re-Analysis (ERA-Interim) and ISCCP projects. The research presented in this paper was carried out on the High Performance Computing Cluster supported by the Research and Specialist Computing Support service at the University of East Anglia. We thank three anonymous reviewers, whose comments helped to improve the manuscript.

\section{APPENDIX A}

\section{Estimation of Surface Solar Radiation Flux from Meteosat-7 OLR}

The surface solar radiation flux measured at the R/V Roger Revelle was averaged to create an hourly time series. A 10-day sample of this time series (blue solid line in Fig. A1a) shows a clear diurnal cycle. Zero flux at night is typically followed by a smooth curve during the day, peaking at midday at approximately $1000 \mathrm{~W} \mathrm{~m}^{-2}$. This is indicative of clear-sky, cloud-free conditions: for example, on 10 October 2011. However, on some days the solar radiation flux is much reduced: for example, peaking at only $400 \mathrm{~W} \mathrm{~m}^{-2}$ on 13 October 2011 . This is indicative of cloudy conditions.

The green dashed line in Fig. A1a shows the hourlymean OLR measured by the Meteosat-7 satellite, extracted for the R/V Roger Revelle location. The OLR is constructed from the infrared and water vapor channels, with 4-km spatial resolution and 30-min temporal resolution, following Roca et al. (2002). The OLR time series are slowly varying (between 260 and $290 \mathrm{~W} \mathrm{~m}^{-2}$ ) on clear-sky days. However, on cloudy days, such as 13 October 2011, there is a sharp decrease in OLR, down to $120 \mathrm{~W} \mathrm{~m}^{-2}$, as the infrared emission is from high, cold cloud tops. Hence, during the daytime on cloudy days, low values of OLR correspond to low values of solar radiation flux.

This relationship is now exploited to derive a predictive model for solar radiation flux, based on OLR. First, the clear-sky diurnal cycle of surface solar radiation flux $\mathrm{SWR}_{\text {clear_sky }}$ is calculated for the R/V Roger Revelle location at $0^{\circ}, 80^{\circ} \mathrm{E}$ (Fig. 1a). Then a predictand time series $y$, of the ratio of the measured surface solar radiation flux SWR to the clear-sky theoretical flux at the same time of day, is computed,

$$
y(t)=\frac{\operatorname{SWR}(t)}{\operatorname{SWR}_{\text {clear_sky }}(t)} .
$$

For clear-sky conditions, $y \approx 1$. For cloudy conditions, $y<1$.

A predictor time series $x$ of the OLR difference from its clear-sky background value is calculated as

$$
x(t)=1-\frac{\operatorname{OLR}(t)}{\mathrm{OLR}_{0}}
$$

where $\mathrm{OLR}_{0}$ is chosen to be a constant $275 \mathrm{Wm}^{-2}$ (Fig. A1a). The analysis is not sensitive to the exact value of this constant.

The predictand solar radiation ratio $y$ data are then linearly regressed against the predictor OLR difference 

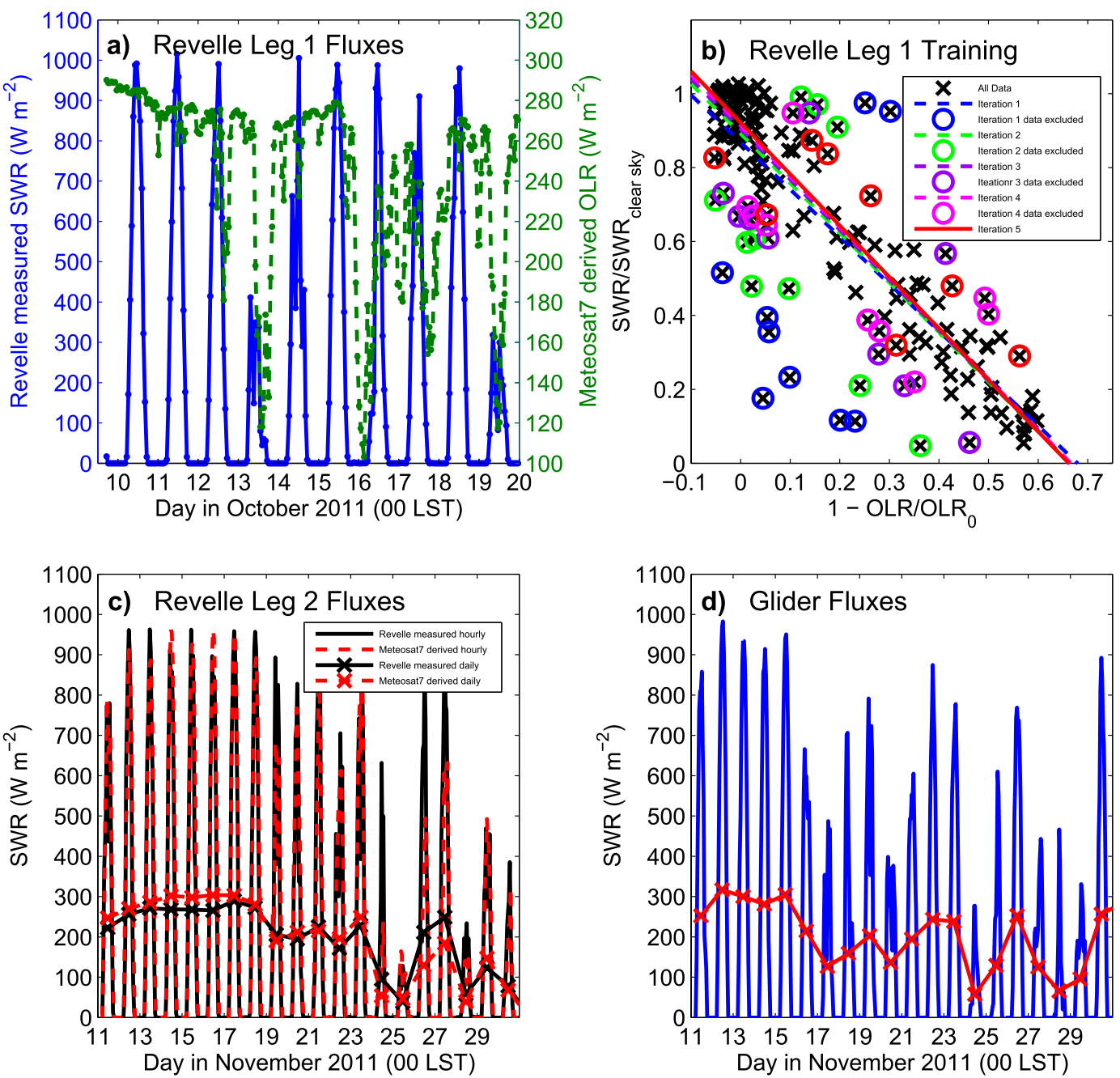

FIG. A1. (a) Time series of SWR (green dashed line) measured by the R/V Roger Revelle and Meteosat-7-derived OLR (blue solid line) at the location of R/V Roger Revelle for the period 10-20 Oct 2011. Tick marks on the horizontal axis correspond to 0000 LST. (b) Scatterplot of Meteosat-7-derived OLR difference (OLR - OLR $)$ at the

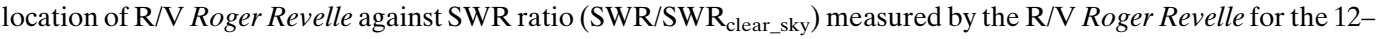
19 Oct 2011 training period. See the main text for details. (c) Time series of SWR measured by the R/V Roger Revelle (black solid lines) and Meteosat-7-derived shortwave radiation flux at the location of R/V Roger Revelle (red dashed lines) for part of the validation period. (d) Time series of Meteosat-7-derived SWR at the glider location for November 2011. Hourly data are shown by the blue line, and daily-mean data are shown by the red line.

$x$ data, as $y=a x+b$. Data during the night $(1800$ 0600 LST) are not used, since SWR $=0$. Also, shortly after sunrise and before sunset, the solar zenith angle is small so the surface solar fluxes are low and the ratio $y$ is subject to large fluctuations. Hence, only data from 0300 to 1000 UTC (0830-1530 LST) are included in the regression calculation, which is performed on a training dataset when the R/V Roger Revelle was continuously on station, from 12 to 19 October 2011.

These points are shown by the black crosses in Fig. A1b. The blue dashed line is the best-fit regression line. There is a clear negative correlation. Low values of surface solar radiation flux ratio $y$ correspond to high values of OLR deficit $x$, as expected on cloudy days. The large cluster of points near $x=0$ and $y=1$ correspond to clear-sky days.

There are two groups of outliers, corresponding to two physical scenarios where the relationship between surface solar radiation flux and OLR is expected to break down. Shallow (strato-) cumulus clouds will reduce the surface solar radiation flux but will not have a large effect on OLR as the low cloud tops are still relatively warm. These points form the outliers at low $x$ and low $y$. High, thin cirrus will not have a large effect on the 
surface solar radiation flux but will efficiently absorb upwelling infrared radiation and re-emit it from the high, cold cloud tops, leading to low OLR. These points form the outliers at high $x$ and high $y$.

Given the physical realism of these outliers, it is reasonable to exclude them from the regression analysis. Hence, the $5 \%$ of the data points that lie farthest from the regression lines are labeled with a blue circle in Fig. A1b. The regression was performed on the remaining $95 \%$ of the data, and the new regression line is shown by the green dashed line in Fig. A1b. This process was then repeated for four iterations. The final (red) regression line in Fig. A1b is very close to the initial regression line, indicating that these outliers do not have a significant effect on the robust underlying relationship between OLR and surface solar radiation flux. The predictive model for surface solar radiation flux is then

$\operatorname{SWR}_{\text {predicted }}(t)=\operatorname{SWR}_{\text {clear_sky }}(t)\left\{a\left[1-\frac{\operatorname{OLR}(t)}{\operatorname{OLR}_{0}}\right]+b\right\}$,

where $a=-1.39$ and $b=0.921$. This is validated on an independent dataset from 11 November to 12 December 2011. The predicted solar radiation flux from a subset of this validation dataset (red dashed lines in Fig. A1c) closely matches the measured flux (black solid lines in Fig. A1c), on both hourly- and daily-mean time scales.

Finally, a time series of predicted surface solar radiation flux was constructed for the glider location, using the coefficients from Eq. (A3). Clear-sky and cloudy days can be clearly identified from an example period of this proxy time series (Fig. A1d). There are distinct differences in daily solar radiation values between the locations of the R/V Roger Revelle (Fig. A1c) and the glider (Fig. A1d). This confirms that the measured solar radiation flux at the $\mathrm{R} / \mathrm{V}$ Roger Revelle could not just be used as a proxy for the flux at the glider location. This novel technique could be applied in a range of situations where the surface solar radiation flux is needed at a certain location, and in situ measurements are taken simultaneously at a different but nearby location with similar cloud characteristics.

\section{APPENDIX B}

\section{Linearization of Surface Fluxes}

Here, the surface fluxes are linearized about the mean state to calculate the flux anomalies due to a surface temperature anomaly $T^{\prime}$.

\section{a. Surface longwave radiative flux}

First, the longwave radiation flux $Q_{\mathrm{LW}}$ is given by

$$
Q_{\mathrm{LW}}=\sigma T_{s}^{4},
$$

where $\sigma=5.67 \times 10^{-8} \mathrm{~W} \mathrm{~m}^{-2} \mathrm{~K}^{-1}$ is the StefanBoltzmann constant and $T_{s}$ is the surface water temperature. This can be linearized about a fixed background temperature $T_{b}=29.0^{\circ} \mathrm{C}=302.15 \mathrm{~K}$ (Fig. 9a), so that $T_{s}=$ $T_{b}+T^{\prime}$ and $T^{\prime} \ll T_{b}$. Neglecting terms that are quadratic or higher order in $T^{\prime}$,

$$
Q_{\mathrm{LW}}=\bar{Q}_{\mathrm{LW}}+Q_{\mathrm{LW}}^{\prime} \approx \sigma T_{b}^{4}+4 \sigma T_{b}^{3} T^{\prime} .
$$

Hence, the background longwave radiation flux is $\bar{Q}_{\mathrm{LW}} \approx$ $472 \mathrm{~W} \mathrm{~m}^{-2}$ and the perturbation longwave radiation flux is $Q_{\mathrm{LW}}^{\prime} \approx 6.3 T^{\prime}$. Using the value of $T^{\prime}=0.2^{\circ} \mathrm{C}$ adopted in section 8 , this gives a value of $Q_{\mathrm{LW}}^{\prime} \approx 1.3 \mathrm{~W} \mathrm{~m}^{-2}$.

\section{b. Surface latent heat flux}

The latent heat flux $Q_{L}$ is given by the bulk aerodynamic formula,

$$
Q_{L}=\rho_{a} L c_{E} V\left[q_{s}\left(T_{s}\right)-q_{a}\right],
$$

where $\rho_{a}$ is the air density, $L=2.5 \times 10^{6} \mathrm{~J} \mathrm{~kg}^{-1}$ is the latent heat of vaporization of water, $c_{E}=1 \times 10^{-3}$ is the exchange coefficient, $V$ is the surface wind speed, $q_{s}$ is the saturation specific humidity, and $q_{a}$ is the specific humidity. Specific humidity is related to saturation vapor pressure $e$ and air pressure $p$ by

$$
q=\frac{\epsilon e}{p-e} \approx \frac{\epsilon e}{p},
$$

where $\epsilon=0.622$ is the ratio of molecular masses of water vapor and dry air and $e \ll p$. The saturation vapor pressure $e_{s}$ is given by the Clausius-Clapeyron relation

$e_{s}=e_{s_{0}} \exp \left[\frac{L}{R_{w}}\left(\frac{1}{T_{b}}-\frac{1}{T_{s}}\right)\right] \approx e_{s_{0}}\left(1+\frac{L T^{\prime}}{R_{w} T_{b}^{2}}\right)$,

where $e_{s_{0}}=4115 \mathrm{~Pa}$ is the saturation vapor pressure at $T_{b}=302.15 \mathrm{~K}$ and $R_{w}=461 \mathrm{~J} \mathrm{~kg}^{-1} \mathrm{~K}^{-1}$ is the specific gas constant for water vapor. Using the ideal gas law $p=\rho_{a} R T_{b}$, where $R=287 \mathrm{~J} \mathrm{~kg}^{-1} \mathrm{~K}^{-1}$ is the specific gas constant for dry air and $\epsilon=R / R_{w}$, the latent heat flux can be decomposed into a background and perturbation term

$$
\begin{aligned}
Q_{L} & =\bar{Q}_{L}+Q_{L}^{\prime} \\
& \approx \rho_{a} L c_{E} V\left[q_{s}\left(T_{b}\right)-q_{a}\right]+\frac{L^{2} c_{E} V \epsilon e_{s_{0}}}{R R_{w} T_{b}^{3}} T^{\prime}
\end{aligned}
$$


Over the tropical ocean, the air temperature is approximately $1^{\circ} \mathrm{C}$ below the sea surface temperature and the relative humidity is $r=80 \%$. The specific humidity is $q_{a}=(r / 100) \times q_{s}\left(T_{a}\right)$, and $V=3 \mathrm{~m} \mathrm{~s}^{-1}$ is a typical value on warm layer days when $T^{\prime}=0.2^{\circ} \mathrm{C}$ (Fig. 10a). Hence, the background latent heat flux is $\bar{Q}_{L} \approx 54 \mathrm{~W} \mathrm{~m}^{-2}$. The perturbation latent heat flux is $Q_{L}^{\prime} \approx 13 T^{\prime} \approx 2.6 \mathrm{~W} \mathrm{~m}^{-2}$.

\section{c. Surface sensible heat flux}

Finally, the sensible heat flux $Q_{S}$ is also given by the bulk aerodynamic formula,

$$
Q_{S}=\rho_{a} c_{p} c_{E} V\left(T_{s}-T_{a}\right),
$$

where $c_{p}=1004 \mathrm{~J} \mathrm{~kg}^{-1} \mathrm{~K}^{-1}$ is the specific heat capacity of dry air. This can also be decomposed into a background and perturbation flux,

$$
\begin{aligned}
Q_{S} & =\bar{Q}_{S}+Q_{S}^{\prime} \\
& =\rho_{a} c_{p} c_{E} V\left(T_{b}-T_{a}\right)+\rho_{a} c_{p} c_{E} V T^{\prime} .
\end{aligned}
$$

The background sensible heat flux is $\bar{Q}_{S}=3.5 \mathrm{Wm} \mathrm{m}^{-2}$ and the perturbation sensible heat flux is $Q_{S}^{\prime} \approx 3.5 T^{\prime} \approx$ $0.7 \mathrm{~W} \mathrm{~m}^{-2}$. This estimate of the anomalous flux is likely to be an overestimate, as it assumes that the air temperature $T_{a}$ remains constant. In reality, the extra upward flux from the sea surface would warm the atmospheric boundary layer and reduce the temperature difference $T_{s}-T_{a}$, thus reducing the values of the anomalous sensible heat flux. The anomalous latent heat flux would be reduced similarly.

\section{REFERENCES}

Bellenger, H., and J.-P. Duvel, 2009: An analysis of tropical ocean diurnal warm layers. J. Climate, 22, 3629-3646, doi:10.1175/ 2008JCLI2598.1.

Bernie, D. J., E. Guilyardi, G. Madec, J. M. Slingo, and S. J. Woolnough, 2007: Impact of resolving the diurnal cycle in an ocean-atmosphere GCM. Part 1: A diurnally forced OGCM. Climate Dyn., 29, 575-590, doi:10.1007/s00382-007-0249-6.

$\_,-, \ldots, \ldots, \ldots$, and J. Cole, 2008: Impact of resolving the diurnal cycle in an ocean-atmosphere GCM. Part 2: A diurnally coupled CGCM. Climate Dyn., 31, 909-925, doi:10.1007/s00382-008-0429-z.

Bowman, K. P., J. C. Collier, G. R. North, Q. Wu, E. Ha, and J. Hardin, 2005: Diurnal cycle of tropical precipitation in Tropical Rainfall Measuring Mission (TRMM) satellite and ocean buoy rain gauge data. J. Geophys. Res., 110, D21104, doi:10.1029/2005JD005763.

Bretherton, F. P., R. E. Davis, and C. B. Fandry, 1976: A technique for objective analysis and design of oceanographic experiments applied to MODE-73. Deep-Sea Res. Oceanogr. Abstr., 23, 559-582, doi:10.1016/0011-7471(76)90001-2.

de Boyer Montégut, C., G. Madec, A. S. Fischer, A. Lazar, and D. Iudicone, 2004: Mixed layer depth over the global ocean:
An examination of profile data and a profile-based climatology. J. Geophys. Res., 109, C12003, doi:10.1029/2004JC002378.

Delnore, V. E., 1972: Diurnal variation of temperature and energy budget for the oceanic mixed layer during BOMEX. J. Phys. Oceanogr., 2, 239-247, doi:10.1175/1520-0485(1972)002<0239: DVOTAE $>2.0 . \mathrm{CO} ; 2$.

Drushka, K., J. Sprintall, S. T. Gille, and S. Wijffels, 2012: In situ observations of Madden-Julian oscillation mixed layer dynamics in the Indian and western Pacific Oceans. J. Climate, 25, 2306-2328, doi:10.1175/JCLI-D-11-00203.1.

Eriksen, C. C., T. J. Osse, R. D. Light, T. Wen, T. W. Lehman, P. L. Sabin, J. W. Ballard, and A. M. Chiodi, 2001: Seaglider: A long-range autonomous underwater vehicle for oceanographic research. IEEE J. Oceanic Eng., 26, 424-436, doi:10.1109/ 48.972073.

Fairall, C. W., E. F. Bradley, J. S. Godfrey, G. A. Wick, J. B. Edson, and G. S. Young, 1996a: Cool-skin and warm-layer effects on sea surface temperature. J. Geophys. Res., 101, 1295-1308, doi:10.1029/95JC03190.

,,- D. P. Rogers, J. B. Edson, and G. S. Young, 1996b: Bulk parameterization of air-sea fluxes for Tropical Ocean-Global Atmosphere Coupled-Ocean Atmosphere Response Experiment. J. Geophys. Res., 101, 3747-3764, doi:10.1029/95JC03205.

Flatau, M., P. J. Flatau, P. Phoebus, and P. P. Niiler, 1997: The feedback between equatorial convection and local radiative and evaporative processes: The implications for intraseasonal oscillations. J. Atmos. Sci., 54, 2373-2386, doi:10.1175/ 1520-0469(1997)054<2373:TFBECA > 2.0.CO;2.

$\mathrm{Fu}, \mathrm{X}$., and B. Wang, 2004: Differences of boreal summer intraseasonal oscillations simulated in an atmosphere-ocean coupled model and an atmosphere-only model. J. Climate, 17, 1263-1271, doi:10.1175/1520-0442(2004)017<1263:DOBSIO>2.0.CO;2.

, J.-Y. Lee, P.-C. Hsu, H. Taniguchi, B. Wang, W. Wang, and S. Weaver, 2013: Multi-model MJO forecasting during DYNAMO/CINDY period. Climate Dyn., 41, 1067-1081, doi:10.1007/s00382-013-1859-9.

Gentemann, C. L., P. J. Minnett, and B. Ward, 2009: Profiles of ocean surface heating (POSH), A new model of upper ocean diurnal warming. J. Geophys. Res., 114, C07017, doi:10.1029/ 2008JC004825.

Gottschalck, J., P. E. Roundy, C. J. Schreck III, A. Vintzileos, and C. Zhang, 2013: Large-scale atmospheric and oceanic conditions during the 2011-12 DYNAMO field campaign. Mon. Wea. Rev., 141, 4173-4196, doi:10.1175/MWR-D-13-00022.1.

Gould, J., and Coauthors, 2004: Argo profiling floats bring new era of in situ ocean observations. Eos, Trans. Amer. Geophys. Union, 85, 185-191, doi:10.1029/2004EO190002.

Gray, W. M., and R. W. Jacobson Jr., 1977: Diurnal variations of deep cumulus convection. Mon. Wea. Rev., 105, 1171-1188, doi:10.1175/1520-0493(1977)105<1171:DVODCC > 2.0.CO;2.

Hall, J. D., A. J. Matthews, and D. J. Karoly, 2001: The modulation of tropical cyclone activity in the Australian region by the Madden-Julian oscillation. Mon. Wea. Rev., 129, 2970-2982, doi:10.1175/1520-0493(2001)129<2970:TMOTCA >2.0.CO;2.

Halpern, D., and R. Reed, 1976: Heat budget of the upper ocean under light winds. J. Phys. Oceanogr., 6, 972-975, doi:10.1175/ 1520-0485(1976)006<0972:HBOTUO > 2.0.CO;2.

Hendon, H. H., and M. L. Salby, 1994: The life cycle of the MaddenJulian oscillation. J. Atmos. Sci., 51, 2225-2237, doi:10.1175/ 1520-0469(1994)051<2225:TLCOTM>2.0.CO;2.

Jerlov, N. G., 1968: Optical Oceanography. Elsevier, 193 pp.

Johnson, R. H., T. M. Rickenbach, S. A. Rutledge, P. E. Ciesielski, and W. H. Schubert, 1999: Trimodal characteristics of 
tropical convection. J. Climate, 12, 2397-2418, doi:10.1175/ 1520-0442(1999)012<2397:TCOTC > 2.0.CO;2.

Klingaman, N. P., S. J. Woolnough, H. Weller, and J. M. Slingo, 2011: The impact of finer-resolution air-sea coupling on the intraseasonal oscillation of the Indian monsoon. J. Climate, 24, 2451-2468, doi:10.1175/2010JCLI3868.1.

Kummerow, C., and Coauthors, 2000: The status of the Tropical Rainfall Measuring Mission (TRMM) after two years in orbit. J. Appl. Meteor., 39, 1965-1982, doi:10.1175/ 1520-0450(2001)040<1965:TSOTTR > 2.0.CO;2.

Matthews, A. J., 2004: The atmospheric response to observed intraseasonal tropical sea surface temperature anomalies. Geophys. Res. Lett., 31, L14107, doi:10.1029/2004GL020474.

Mobley, C. D., 1994: Light and Water: Radiative Transfer in Natural Waters. Academic Press, 592 pp.

Moum, J., and Coauthors, 2013: Air-sea interactions from westerly wind bursts during the November 2011 MJO in the Indian Ocean. Bull. Amer. Meteor. Soc., 95, 1185-1199, doi:10.1175/ BAMS-D-12-00225.1.

Mujumdar, M., K. Salunke, S. A. Rao, M. Ravichandran, and B. N. Goswami, 2011: Diurnal cycle induced amplification of sea surface temperature intraseasonal oscillations over the Bay of Bengal in summer monsoon season. IEEE Geosci. Remote Sens. Lett., 8, 206-210, doi:10.1109/LGRS.2010.2060183.

Neelin, J. D., D. S. Battisti, A. C. Hirst, F.-F. Jin, Y. Wakata, T. Yamagata, and S. E. Zebiak, 1998: ENSO theory. J. Geophys. Res., 103, 14261-14290, doi:10.1029/97JC03424.

O'Connor, B. M., R. A. Fine, and D. B. Olson, 2005: A global comparison of subtropical underwater formation rates. DeepSea Res., 52, 1569-1590, doi:10.1016/j.dsr.2005.01.011.

Ohlmann, J. C., D. A. Siegel, and L. Washburn, 1998: Radiant heating of the western equatorial Pacific during TOGACOARE. J. Geophys. Res., 103, 5379-5395, doi:10.1029/ 97JC03422.

Paulson, C. A., and J. J. Simpson, 1977: Irradiance measurements in the upper ocean. J. Phys. Oceanogr., 36, 1722-1735, doi:10.1175/1520-0485(1977)007<0952:IMITUO > 2.0.CO;2.

Peatman, S. C., A. J. Matthews, and D. P. Stevens, 2014: Propagation of the Madden-Julian oscillation through the Maritime Continent and scale interaction with the diurnal cycle of precipitation. Quart. J. Roy. Meteor. Soc., 140, 814-825, doi:10.1002/ qj. 2161.

Praveen Kumar, B., J. Vialard, M. Lengaigne, V. S. N. Murty, and M. J. McPhaden, 2012: TropFlux: Air-sea fluxes for the global tropical oceans-Description and validation. Climate Dyn., 38, 1521-1543, doi:10.1007/s00382-011-1115-0.

Price, J. F., R. A. Weller, and R. Pinkel, 1986: Diurnal cycling: Observations and models of the upper ocean response to diurnal heating, cooling, and wind mixing. J. Geophys. Res., 91, 8411-8427, doi:10.1029/JC091iC07p08411.

Prytherch, J., J. T. Farrar, and R. A. Weller, 2013: Moored surface buoy observations of the diurnal warm layer. J. Geophys. Res., 118, 4553-4569, doi:10.1002/jgrc.20360.

Reynolds, R. W., N. A. Rayner, T. M. Smith, D. C. Stokes, and W. Wang, 2002: An improved in situ and satellite SST analysis for climate. J. Climate, 15, 1609-1625, doi:10.1175/ 1520-0442(2002)015<1609:AIISAS > 2.0.CO;2.
Roca, R., M. Viollier, L. Picon, and M. Desbois, 2002: A multisatellite analysis of deep convection and its moist environment over the Indian Ocean during the winter monsoon. J. Geophys. Res., 107, doi:10.1029/2000JD000040.

Schott, F. A., S. Xie, and J. P. McCreary, 2009: Indian Ocean circulation and climate variability. Rev. Geophys., 47, RG1002, doi:10.1029/2007RG000245.

Seo, K.-H., J.-K. E. Schemm, W. Wang, and A. Kumar, 2007: The boreal summer intraseasonal oscillation simulated in the NCEP Climate Forecast System: The effect of sea surface temperature. Mon. Wea. Rev., 135, 1807-1827, doi:10.1175/MWR3369.1.

Shinoda, T., 2005: Impact of the diurnal cycle of solar radiation on intraseasonal SST variability in the western equatorial Pacific. J. Climate, 18, 2628-2636, doi:10.1175/JCLI3432.1.

,- H. H. Hendon, and J. Glick, 1998: Intraseasonal variability of surface fluxes and sea surface temperature in the tropical western Pacific and Indian Oceans. J. Climate, 11, 1685-1702, doi:10.1175/1520-0442(1998)011<1685:IVOSFA>2.0.CO;2.

_ T. T. Jensen, M. K. Flatau, S. Chen, W. Han, and C. Wang, 2013: Large-scale oceanic variability associated with the Madden-Julian oscillation during the CINDY/DYNAMO field campaign from satellite observations. Remote Sens., 5, 2072-2092, doi:10.3390/rs5052072.

Soloviev, A., and R. B. Lukas, 1997: Observations of large diurnal warming events in the near-surface layer of the western equatorial Pacific warm pool. Deep-Sea Res. I, 44, 1055-1076, doi:10.1016/S0967-0637(96)00124-0.

Sui, C. H., X. Li, K. M. Lau, and D. Adamec, 1997: Multiscale air-sea interactions during TOGA COARE. Mon. Wea. Rev., 125, 448 462, doi:10.1175/1520-0493(1997)125<0448:MASIDT>2.0.CO;2.

Webber, B. G. M., A. J. Matthews, and K. J. Heywood, 2010: A dynamical ocean feedback mechanism for the Madden-Julian oscillation. Quart. J. Roy. Meteor. Soc., 136, 740-754, doi:10.1002/qj.604.

,,,--- J. Kaiser, and S. Schmidtko, 2014: Seaglider observations of equatorial Indian Ocean Rossby waves associated with the Madden-Julian oscillation. J. Geophys. Res. Oceans, 119, 3714-3731, doi:10.1002/2013JC009657.

Webster, P. J., C. A. Clayson, and J. A. Curry, 1996: Clouds, radiation, and the diurnal cycle of sea surface temperature in the tropical western Pacific. J. Climate, 9, 1712-1730, doi:10.1175/ 1520-0442(1996)009<1712:CRATDC > 2.0.CO;2.

Wheeler, M. C., and H. H. Hendon, 2004: An all-season real-time multivariate MJO index: Development of an index for monitoring and prediction. Mon. Wea. Rev., 132, 1917-1932, doi:10.1175/1520-0493(2004)132<1917:AARMMI>2.0.CO;2.

Woolnough, S. J., J. M. Slingo, and B. J. Hoskins, 2000: The relationship between convection and sea surface temperature on intraseasonal timescales. J. Climate, 13, 2086-2104, doi:10.1175/1520-0442(2000)013<2086:TRBCAS > 2.0.CO;2.

_ F. Vitart, and M. A. Balmaseda, 2007: The role of the ocean in the Madden-Julian oscillation: Implications for MJO prediction. Quart. J. Roy. Meteor. Soc., 133, 117-128, doi:10.1002/qj.4.

Yu, L., X. Jin, and R. A. Weller, 2008: Multidecade global flux datasets from the Objectively Analyzed Air-Sea Fluxes (OAFlux) project: Latent and sensible heat fluxes, ocean evaporation, and related surface meteorological variables. Woods Hole Oceanographic Institution Tech. Rep. OA-2008-01, 64 pp. 